\title{
Imaging Methodology for Hip Preservation: Techniques, Parameters, and Thresholds
}

\author{
Vasco V. Mascarenhas, MD, MBA ${ }^{1}$ Olufemi R. Ayeni, MD, PhD, FRCSC ${ }^{2}$ Niels Egund, MD, DMSc ${ }^{3}$ \\ Anne G. Jurik, MD, DMSc ${ }^{3}$ António Caetano, $M^{4}$ Miguel Castro, $M^{5}$ João Novo ${ }^{1}$ Sara Gonçalves ${ }^{1}$ \\ Reto Sutter, MD 6
}

${ }^{1}$ MSK Imaging Unit (UIME), Imaging Center, Hospital da Luz, Lisbon, Portugal

2 Division of Orthopaedic Surgery, McMaster University, Ontario, Canada

${ }^{3}$ Department of Radiology, Aarhus University Hospital, Aarhus, Denmark

${ }^{4}$ Hospital Curry Cabral, Lisbon, Portugal

${ }^{5}$ Centro Hospitalar do Algarve, Faro, Portugal

${ }^{6}$ Department of Radiology, Balgrist University Hospital, University of

Zurich, Zurich, Switzerland

Address for correspondence Vasco V. Mascarenhas, MD, MBA, MSK Imaging Unit (UIME), Hospital da Luz, Lisbon, Portugal (e-mail:vmascarenhas@me.com).

Semin Musculoskelet Radiol 2019;23:197-226.

\begin{abstract}
Keywords

- imaging

- methodology

- reference intervals

- femoroacetabular impingement

- hip preservation

The concept of hip impingement and hip-preserving surgery has been appreciated in more detail since 2001 when a new surgical approach was reported and a hypothesis linking femoroacetabular impingement (FAl) with osteoarthritis was presented. Paralleling the introduction of hip arthroscopy, these events led to an increasing interest in the hip, and the number of publications has risen rapidly over the past 15 years, despite limited evidence levels and inconsistent methodology. Accordingly, etiology, diagnosis, prognosis, and the effects of treatment for FAl are still elusive due to a number of uncertainties and a lack of clear diagnostic criteria.

Future research must focus on developing high-quality scientific studies, so thorough and reproducible methodology is needed. This review provides researchers, radiologists, and clinicians with a comprehensive approach to hip imaging with a focus on strategies to help guide the clinical diagnosis. Using evidence from current literature and knowledge from experienced clinicians, some of the imaging methodology challenges are deciphered.
\end{abstract}

Assessing young adults with hip pain can be challenging for the clinician. Although various features from a patient's history and physical examination can be helpful in reaching the correct diagnosis, no particular component of either is entirely diagnostic. ${ }^{1}$

A vast differential diagnosis of conditions may cause hip pain, and the symptomatic patient has often been assessed by several practitioners with different perspectives. ${ }^{2}$ With regard to the clinical assessment, the multitude of physical examination maneuvers have varying levels of sensitivity and specificity, thereby limiting their predictive value. In addition, there is a general lack of consistency when execut- ing physical examination maneuvers used to assess the symptomatic hip. ${ }^{3}$

Subsequently, confirmatory imaging is considered an essential piece to completing the diagnosis and consolidating treatment plans. ${ }^{4}$ An accurate diagnosis ensures that both the clinician and patient can pursue the optimal treatment strategy. The modalities for imaging the hip include a spectrum of testing procedures that provide detail including but not limited to the bony and soft tissue anatomy of the hip and the surrounding periarticular structures. The combination of plain radiographs (XR), magnetic resonance imaging (MRI), and computed tomography (CT) can be helpful when
Issue Theme Hip and Advanced Musculoskeletal Imaging; Guest Editors, Vasco V. Mascarenhas, MD, MBA and Alberto Vieira, MD
Copyright @ 2019 by Thieme Medical Publishers, Inc., 333 Seventh Avenue, New York, NY 10001, USA. Tel: +1(212) 584-4662. ISSN 1089-7860. 
determining the etiology of hip pain. ${ }^{5}$ Further, these modalities can be used individually or collectively to obtain a comprehensive assessment of the hip joint. The use of these modalities requires accurate technique, proper positioning of the patient, and, most importantly, a precise interpretation of results. Their consistent use with standardized and reproducible thresholds further enhances patient care and the ability to conduct academic investigations and research. ${ }^{5,6}$ It is this combination of features of the patient's history, clinical findings on examination, and imaging findings that will allow a comprehensive assessment of the patient with a symptomatic hip.

This article provides radiologists, clinicians, and researchers with a thorough and comprehensive approach to hip imaging with a focus on imaging strategies to help guide the clinical diagnosis. Using evidence from current literature and knowledge from experienced clinicians, some of the imaging challenges that clinicians face when evaluating the hip are deciphered.

\section{Techniques}

Presently, XR and MRI are the standard imaging modalities used for diagnosing hip impingement/instability, planning treatment, and outcome assessment. ${ }^{7,8}$ Adequate preoperative characterization and assessment of the osseous morphology is of paramount importance to ensure optimal surgical outcomes for such populations. As an initial diagnostic clinical approach, anteroposterior (AP) pelvis and lateral hip radiographs ${ }^{4}$ have traditionally been used and will continue to be ( $\mathbf{- F i g . ~} \mathbf{1}$ ).

Nonetheless, relying on XR for the characterization of complex hip pathomorphologies, such as in femoroacetabular impingement (FAI), faces considerable constraints mainly related to inconsistencies in techniques, positioning, imaging quality, and reliability of reports. ${ }^{9-11}$

With regard to femoral morphology, some authors have demonstrated that the use of a three-view series (AP pelvis, Dunn 45-degree view, and frog-lateral radiographs), ${ }^{12}$ a twoview series (Meyer lateral and Dunn 90-degree views), ${ }^{13}$ or even a one-view series (Dunn 45 -degree view) ${ }^{14}$ is adequately sensitive for the evaluation of a cam deformity. ${ }^{14}$ In fact, the two-view series just described was reported to provide the most effective predictions of the three-dimensional (3D) shape of the proximal femur. ${ }^{4,13}$ Conceptually, given that the hip is a 3D anatomical structure, fundamental radiologic parameters currently used to diagnose prearthritic hip conditions (i.e., two-dimensional [2D] parameters) would be increasingly facilitated with MRI and CT volumetric imaging (i.e., assessing both $2 \mathrm{D}$ and $3 \mathrm{D}$ parameters).

Accordingly, 3D assessment of hip morphology has gained increasing attention because it is considered the gold standard for detecting hip deformities. Detection of cam-type FAI on 3D imaging studies (CT or MRI) with radial oblique reformats/acquisitions spanning the anterosuperior neck has gradually been established as the gold standard for morphological assessment. ${ }^{12,15}$ In addition, joint modeling,

\begin{tabular}{|c|c|c|}
\hline 1 & HISTORY, SIGNS, and SYMPTOMS & CUNICAL ASSESSMENT \\
\hline 2 & JOINT MORPHOLOGY & $\begin{array}{c}\text { PELVIC RADIOGRAPH } \\
\text { MRI }\end{array}$ \\
\hline 3 & ARTICULAR DAMAGE & MRI \\
\hline 4 & DIFFERENTIAL DIAGNOSIS & $\begin{array}{l}\text { CUINICAL ASSESSMENT } \\
\text { MRI }\end{array}$ \\
\hline 5 & FINAL DIAGNOSIS & CUINICAL ASSESSMENT \\
\hline 6 & TREATMENT & CUINICAL ASSESSMENT \\
\hline 7 & FOLLOW-UP & $\begin{array}{c}\text { CUNICAL ASSESSMENT } \\
\text { MRI }\end{array}$ \\
\hline
\end{tabular}

Fig. 1 Algorithm for evaluation of hip pain used at Hospital da Luz in Lisbon. First, the diagnosis of femoroacetabular impingement is suspected based on patient history and clinical findings. Next, the hip is assessed on an anteroposterior pelvic radiograph (evaluating the acetabulum and pincer morphology) and on a 45-degree Dunn hip-centered radiographic view. Using magnetic resonance imaging, the morphology of the femur is evaluated (cam morphology and femoral torsion), and damage to the cartilage and labrum is depicted. Finally, all data are combined to reach a diagnosis and define the appropriate course of treatment. Follow-up is based on clinical assessment and imaging when needed.

based on a 3D data set, is used to simulate the effect of osseous morphologies of the hip on joint range of motion, allowing the performance of a virtual impingement analysis. ${ }^{13,16}$ Currently, however, the clinical applicability of these models for routine FAI diagnostics has not been validated.

\section{Radiographic Techniques and Projections}

XR studies play a critical role in the evaluation and detection of early hip structural disorders, such as developmental dysplasia of the hip (DDH), ${ }^{17} \mathrm{FAI}$, and osteoarthritis (OA). ${ }^{18}$ These studies may provide the correct information, as long as they are acquired with a reliable standard technique., 9

Different techniques are described for the axial/lateral view of the hip and also for the AP view of the hip/pelvis that are performed to answer specific questions (online -Supplementary Table 1). These views allow assessment of joint congruency and both femoral (head sphericity, headneck offset, and torsion) and acetabular morphology (coverage, orientation, and depth). ${ }^{9,19}$

\section{Anteroposterior Pelvis}

For the pelvis AP radiograph, the legs must be internally rotated 15 degrees to compensate for femoral antetorsion. The central beam is centered to the midpoint between the upper border of the symphysis and a line connecting the two anterior superior iliac spines ${ }^{9,19}$ (- Fig. 2a, b).

Other technical aspects are paramount to acknowledge including the following:

1. Conical projection ${ }^{20}$ : XR is based on a point-shaped X-ray source with conical projection. Therefore, distortion of the pelvic anatomy is unavoidable (the closer an object is 


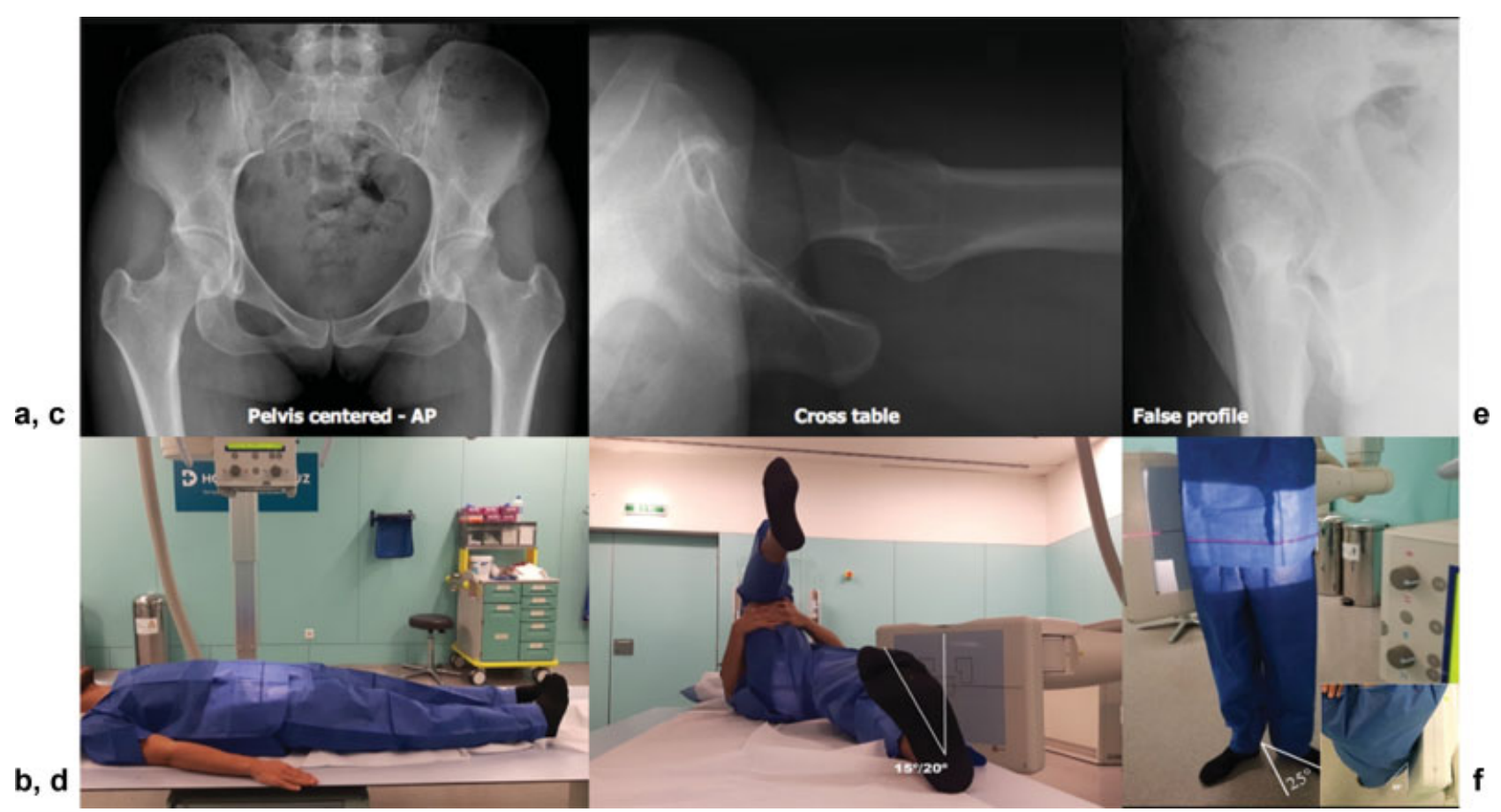

Fig. 2 Radiographic images and positioning in different hip and pelvic views. (a, b) Supine pelvic anteroposterior (AP) radiograph. (c, d) Crosstable lateral view of the left hip. (e, f) False profile of Lequesne of the right hip.

located to the beam source, the more lateral it will be projected).

2. Film-tube distance ${ }^{9,19}$ : This affects hip anatomy on the XR. For example, by increasing film-tube distance, the apparent acetabular anteversion increases (film-tube distance should be $\sim 120 \mathrm{~cm}$ ).

3. Centering and direction of the X-ray beam ${ }^{19}$ : Centering is one of the most important factors influencing pelvic anatomy. To avoid distortion, the craniocaudal angle of the beam is standardized so the sacrococcygeal joint is 1 to $3 \mathrm{~cm}$ from the superior aspect of the pubic symphysis. This ensures adequate representation of the acetabulum (by lowering the center of the beam or by moving it to the center of the hip, the apparent acetabular anteversion increases).

4. Pelvic orientation ${ }^{20}$ : Orientation can vary in three dimensions: obliqueness, rotation, and tilt. Although variations in obliquity and rotation can be decreased by a standardized acquisition technique, pelvic tilt can vary substantially. Pelvic tilt mainly affects the apparent anteversion of the acetabulum (with increasing pelvic tilt, the apparent acetabular anteversion decreases).

Proper positioning on an AP pelvic radiograph is recognized when ${ }^{9}(1)$ the greater trochanter is seen laterally, and the lesser trochanter is partially superimposed on the femoral neck, (2) the obturator rings and acetabular teardrops are symmetrical, and (3) the midsacral line aligns with the pubic symphysis.

\section{Supine versus Weightbearing AP Pelvic Radiograph}

$\mathrm{XR}$ performed in the supine position is preferred by some authors because the necessary image quality can be secured.
Additionally, they can be directly compared with XR performed intraoperatively or at follow-up during early rehabilitation and restricted weightbearing. ${ }^{21}$ Conversely, weightbearing radiographs reflect functional anatomical positioning and are recommended by some orthopaedic surgeons as radiographic signs of the acetabular version/coverage vary between the supine and standing positions. In clinical entities where acetabular evaluation is of paramount importance (such as pincer FAI and DDH), weightbearing radiographs should be obtained, given that they account for the differences in pelvic flexion-extension. ${ }^{20}$ However, these signs are common on standing radiographs of normal individuals and less reliable compared with measurements on CT and MRI. ${ }^{22,23}$ Additional functional views may occasionally be necessary. For instance, abduction views are helpful to differentiate between subluxation and true joint space narrowing in $\mathrm{DDH}^{24}$

\section{Lateral Views}

The most studied and reliable lateral views of the hip include the frog-leg, Lauenstein, cross-table, Ducroquet, Lequesne, and Dunn views (that can be performed with different approaches, namely, Dunn 45 degrees, modified Dunn 45 degrees, or Dunn 90 degrees). ${ }^{25,26}$ These views mainly assess femoral morphology and femoral anterior coverage (-Figs. 2-4).

Femoral head-neck (FHN) asphericity is most often localized in the anterosuperior region. ${ }^{27}$ Although not consensual, these asphericities are usually best shown with a Dunn 45-degree view $^{28,29}$ because it is thought to be at least equal to other lateral views in the initial evaluation of cam morphology. ${ }^{25,30}$ Using this lateral view as the radiographic standard for the evaluation of FAI provides clinicians with the highest probability of demonstrating a cam morphology $\mathrm{y}^{28-30}(\mathbf{- F i g . ~ 3 a , ~ b )}$. 


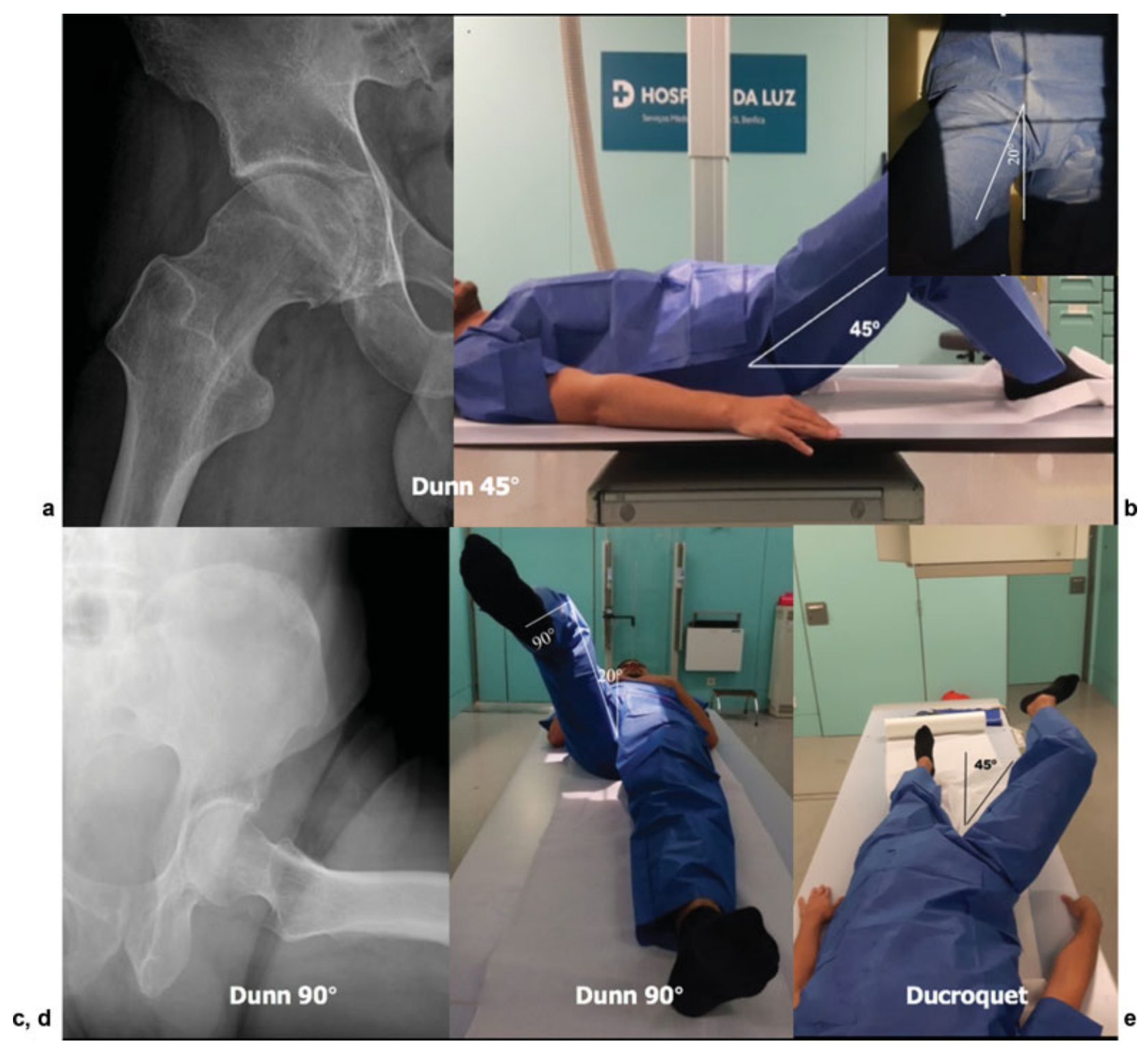

Fig. 3 Radiographic images and positioning in different lateral hip views. (a, b) Dunn 45-degree radiograph. (c, d) Dunn 90 degrees. (e) Ducroquet view. Note that the Dunn 90-degree and Ducroquet views are differentiated by different degrees of hip abduction ( 20 and 45 degrees, respectively).

The Dunn-Rippstein view (Dunn 90 degrees) (-Fig. 3c, d) was originally introduced to measure femoral antetorsion ${ }^{31}$; however, compared with CT- or MRI-based measurements, it is much less accurate and susceptible to patient malpositioning. ${ }^{32}$ This projection can be used as an alternative to the axial cross-table view to evaluate the anterior and posterior contour of the FHN junction.

With respect to combinations of lateral radiographic projections, some authors have demonstrated that the use of a three-view or two-view series provides the best approach for the evaluation of a cam morphology. ${ }^{12-14}$ However, it is notable that the $\alpha$ angle and head-neck offset measurements from these and other XR views were reported to describe no more than $50 \%$ of the overall variation of the proximal femur shape. ${ }^{13}$ In addition, less radiation exposure and affordable care have to be taken into account. Further research should validate current evidence supporting that the Dunn 45-degree lateral view is superior to all other lateral views in the initial demonstration of a cam morphology. Currently, it can be regarded as the first-line diagnostic radiographic imaging for this purpose.

\section{Key Points}

1. FHN asphericity is most often localized in the anterosuperior region.

2. Hip morphology is initially best assessed with an AP pelvis radiograph and a Dunn 45-degree view.

\section{MRI Protocol for the Young Hip Patient}

Presently, arthrographic and nonarthrographic MRI with radial sequences and version measurement are the 


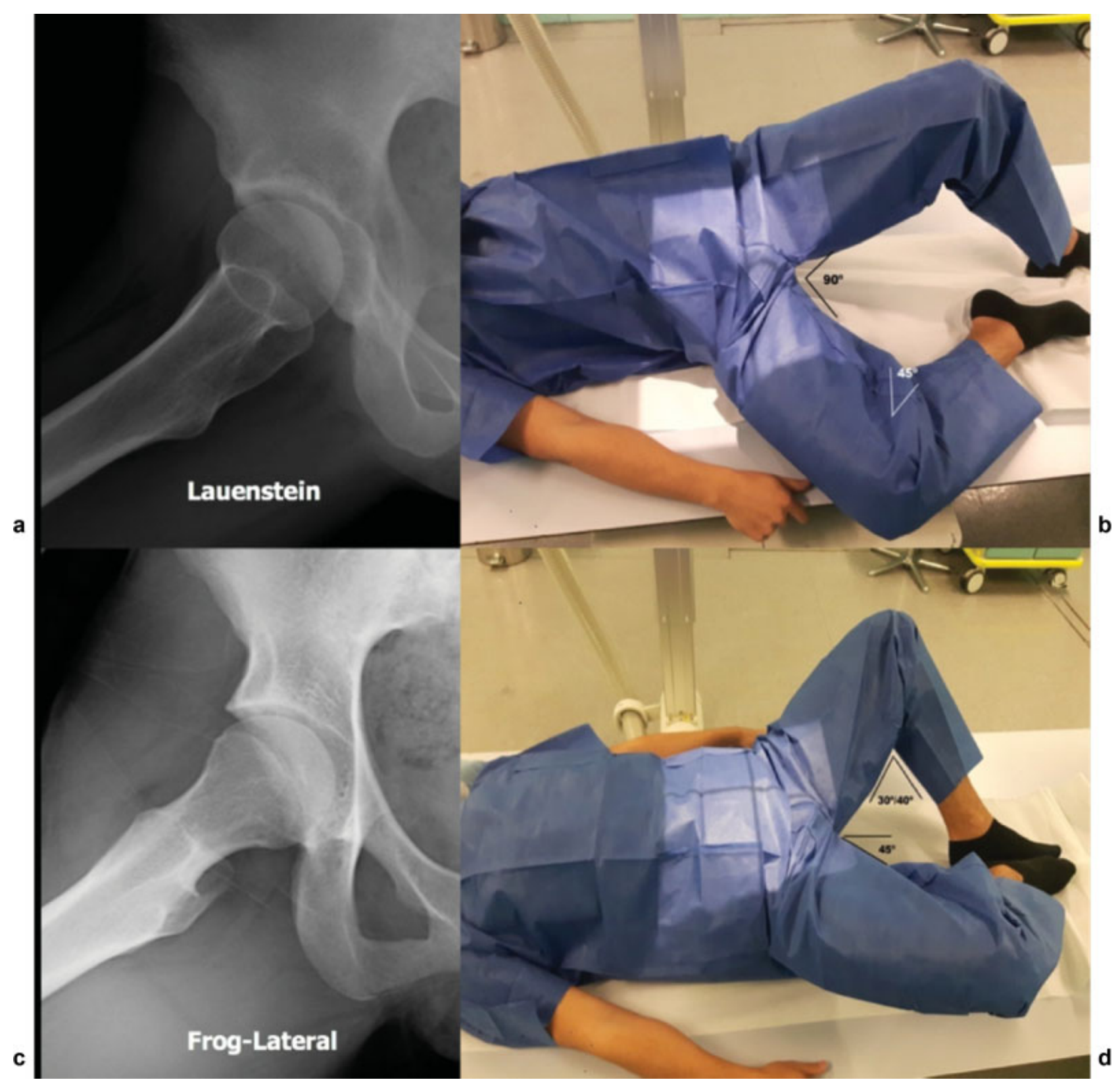

Fig. 4 Radiographic images and positioning in different lateral hip views. (a, b) Lauenstein radiograph. (c, d) Frog-lateral view.

established gold standards for the advanced imaging workup of young patients with hip pain, ${ }^{8,33}$ particularly if a detailed and thorough protocol is used (-Fig. 5). Until now, there were clear limitations in the ability of MRI to evaluate tridimensional bone morphology, ${ }^{34}$ although its value in assessing periarticular soft tissues and intra-articular damage has remained undisputed.

Despite inherently greater radiation doses, CT provides the advantages of 3D assessment for preoperative planning, version analysis, and assessment of global coverage while facilitating postacquisition correction of positioning errors. ${ }^{35}$ Although its value in relation to hip pain has not been adequately studied, $\mathrm{CT}$ is traditionally considered the best imaging modality for the assessment of bony morphology. ${ }^{34}$ This imaging technique involves inherent higher $\operatorname{costs}^{36}$ (compared with XR) and increased radiation exposure. $^{37}$ The total average effective dose of an AP pelvis radiograph and a Dunn lateral view is $1.2 \mathrm{mSv}$ (range: 0.4$2.4 \mathrm{mSv}$ ), whereas that of a pelvis CT scan is currently $6.0 \mathrm{mSv}$ (range: 3.3-10.0 mSv). ${ }^{37}$ Recently, advanced CT protocols were developed to decrease this exposure by at least a factor of 2 to $3 .^{38}$ Because advanced imaging continues to be used for the assessment of FAI and DDH, careful consideration of cumulative radiation exposure is imperative.

MRI with 3D reformats has shown promise and proved to be effective in evaluating shoulder anatomy and instability. Transposing this application to the hip with similar reliability would clearly obviate the need for CT. Evidence was recently uncovered showing that 3D MRI can be used to accurately diagnose and quantify FAI typical osseous pathologic 


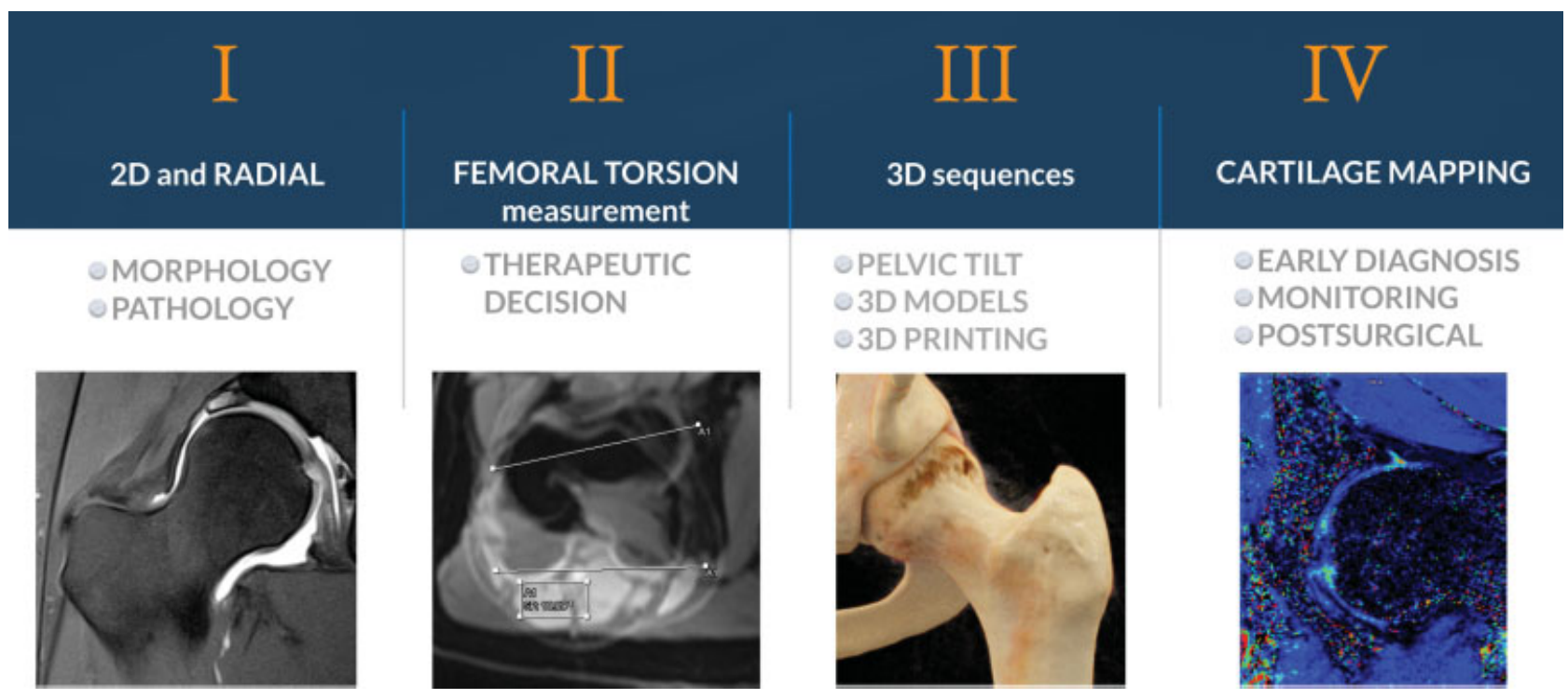

Fig. 5 Schematic figure representing proposed complete magnetic resonance imaging protocol for the assessment of the young hip. Twodimensional (2D) sequences with radial imaging are used for the assessment of morphology and pathology. Assessment of the femoral torsion is performed (minimum protocol for the young patient with hip pain). Optional three-dimensional (3D) sequences may be obtained to allow for correction of pelvic tilt, 3D modeling, 3D printing, and virtual range of motion simulations. Finally, an optional research sequence that allows for cartilage biochemical mapping can be performed.

conditions, thus eliminating the need for 3D CT. ${ }^{39,40}$ The use of MRI was reported to spare each patient an average radiation effective dose of $3.09 \mathrm{mSv}{ }^{39}$

Standard MRI bone modeling is not currently practiced or widely used due to factors such as cost and unavailable automatic segmentation software. Research aimed at developing the necessary protocol to integrate advanced modeling (e.g., statistical shape modeling) into clinical practice is valuable because it could aid in assessing young pre-arthritic patients. ${ }^{41}$ With regard to clinical outcomes, future research is needed to determine if adding advanced 3D hip imaging for presurgical planning would, in fact, improve therapeutical outcomes for young patients.

\section{Key Point}

MRI with a radial sequence/reformat and femoral antetorsion assessment should be viewed as the minimum ideal protocol to assess hip morphology in the young adult with hip pain.

\section{Moving from Plain Radiography to CT and MRI}

\section{Parameters}

\section{General Considerations}

Regardless of the imaging method used to study the hip, multiple parameters, initially described for XR, have been used indiscriminately to measure osseous morphology with other imaging techniques. When new imaging modalities are utilized, their performances must be assessed before they can be used in clinical practice. ${ }^{42,43}$

Interchangeability of imaging methodologies to address quantitative measurements has not been widely tested for most 2D hip parameters. In clinical practice, an interchangeability has often been assumed between acetabular and femoral parameters on XR and 2D CT/MRI. This is particularly important when assessing the acetabular component because acetabular orientation, version, and coverage are susceptible to a multitude of positional variations in all planes.

\section{Limitations}

Accordingly, precise methodology addressing how to measure these parameters is also missing. Unfortunately, no standardized protocols for CT or MRI currently exist that can account for major limitations when using these modalities, namely:

1. Coronal plane alignment for measurement of the acetabular lateral coverage (center-edge angle [CEA] and acetabular inclination). Traditionally, an underlying assumption was that a coronal plane (orthogonal to the axial plane passing through the center of the femoral heads at their greatest diameters on axial reference images) coincides with the lateral acetabular rim and represents lateral acetabular coverage. However, multiple factors can influence pelvic position and its inherent relation with the femoral heads, rendering this assumption invalid. ${ }^{44}$

2. Slice selection on coronal 2D imaging (MRI) could influence the measurement of acetabular coverage. ${ }^{42}$

3. Pelvic malpositioning and lumbar factors such as lumbar lordosis/kyphosis and associated pelvic tilt abnormalities 
may be associated with apparent overcoverage or undercoverage. $^{20}$

4. Precise identification of bony landmarks has always been somewhat problematic in younger children, where the radiolucent acetabular growth cartilage forms much of the acetabular rim. ${ }^{45}$

5. Other anatomical factors need consideration such as secondary morphological changes in the labrum, illdefined margins of the acetabular rim, and femoral head asphericity.

It is unclear at present how these secondary abnormalities should be accounted for when standardizing MRI and CT evaluation of the pelvis. These findings highlight the urgent need to develop a standardized technique for the measurement of hip parameters that subtracts potential variations in pelvic tilt abnormality and 3D hip morphology.

\section{Plain Radiographs and CT}

Scarce literature has specifically addressed the interchangeability of hip parameters between XR and CT. Similar angle measurements were reported by some authors between these modalities, with $\mathrm{CT}$ measurements correlating well with some radiographic parameters, ${ }^{46}$ namely, acetabular inclination, lateral center-edge angle (L-CEA), and $\alpha$ angles (intermodality reliability, as well as intra- and interrater reliability, of both modalities showed excellent performance ${ }^{46}$ ). However, this was only achievable if a standardized procedure was used. ${ }^{47}$

These results complement other studies showing consistencies associated with CT-facilitated assessments of the pre-arthritic hip. ${ }^{12,46}$ However, other authors found that measurement of the Wiberg center-edge angle (W-CEA) consistently increased on $\mathrm{CT}$ in accordance with clinical etiology (W-CEA was larger by a mean of 4.9-5.1 degrees on CT in hips with DDH), emphasizing the need for standardization and validation of CT-based measurements. ${ }^{44}$

\section{Plain Radiographs and MRI}

Scarce literature has specifically addressed interchangeability of hip parameters between XR and MRI. Currently, it is largely unknown whether standard morphometric parameters of the hip measured on MRI are comparable with radiographs. ${ }^{42}$

Stelzeneder et $\mathrm{al}^{42}$ showed that MRI provides similar morphometric measurements to radiography for most hip parameters (namely, W-CEA, acetabular inclination, and extrusion index) but not for the anterior center-edge angle (A-CEA). With regard to W-CEA, the estimated differences were within or below the range of previously reported radiographic interrater differences for this parameter, ${ }^{43,48}$ suggesting that MRI can be used to measure a radiographlike W-CEA angle with sufficient precision. ${ }^{42}$ Interestingly, the off-center slice (i.e., $10 \mathrm{~mm}$ anterior to the center of the femoral heads) was shown to be the most accurate compared with radiographic $\mathrm{W}$-CEA.

However, considering all parameters, it is unclear why there is less agreement (or with conflicting results) between
MRI (and also CT) concerning L-CEA and femoral neck shaft angles compared with other assessments of osseous morphology. 39

\section{Standardization Protocol}

Despite all efforts to standardize patient positioning before image acquisition, some degree of pelvic rotation and tilting is frequent. To standardize pelvic malpositioning, 3D pelvic images should be processed via image manipulation to correct for pelvic tilt and rotations. However, it can be argued that pelvic orientation after correction might not represent the patient's functional alignment. However, it certainly allows for accurate and reproducible measurements as previously reported ${ }^{45}$ and is currently used in multiple centers (-Fig. 6).

Newer methods for the measurement of hip morphology, ideally involving the determination of 3D measurements with 3D MRI and low-dose 3D CT, may be warranted to improve the quality of diagnostic preoperative imaging and subsequent clinical decision making. ${ }^{39,44}$

\section{Key Points}

1. Hip measurements interchangeability between XR, CT, and MRI should be done with great caution and following a strict standardized protocol.

2. A radiation-free 3D MRI protocol can facilitate such measurements.

\section{Radiologic Signs and Parameters (XR and Cross-Sectional)}

\section{What They Are and How to Measure Them}

Overall, the most commonly described parameters to assess acetabular morphology can be divided according to the main features that they measure, that is to say, depth, coverage, and orientation (-Fig. 7 and - Table 1).

Similarly, the most commonly described parameters to assess femoral morphology can be divided according to the main features that they measure, namely joint congruency, femoral head sphericity, and other important parameters such as neck orientation in the coronal (neck-shaft angle) and in the axial (torsion) planes (-Fig. 8 and -Table 2).

\section{Thresholds: A Scoping Review}

Thresholds of hip quantitative parameters have been extensively debated, mainly due, on one hand, to a lack of agreement regarding which imaging method should be used to establish such thresholds ${ }^{5}$ or, on the other hand, due to the lack of consensus regarding what kind of reference interval is ideal $^{49}$ in the setting of hip-preserving surgery.

Reference intervals (RefInt) are the most widely used tools for the interpretation of hip quantitative measurements. These involve obtaining samples from a healthy population and then 


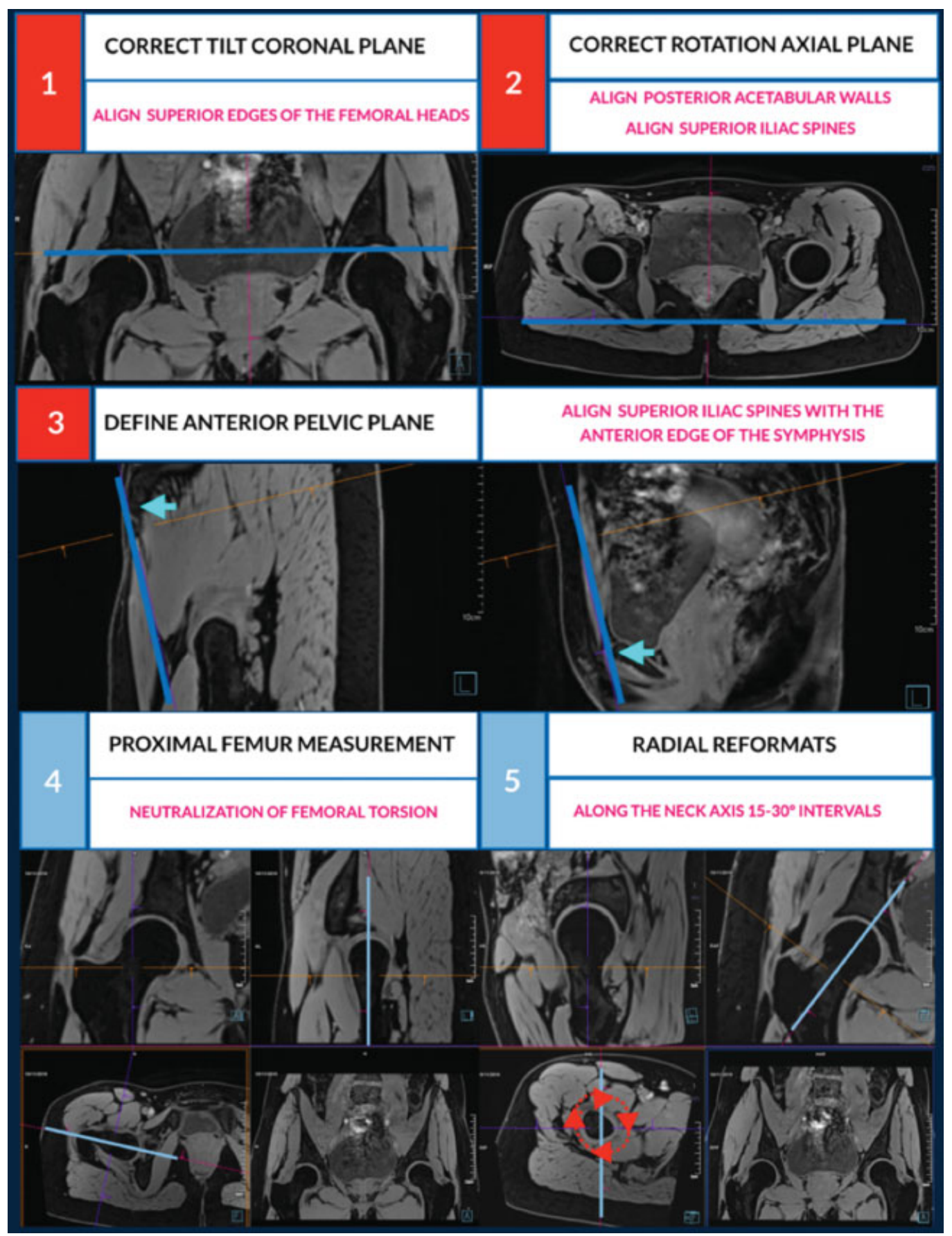

Fig. 6 Steps to use volumetric imaging and obtain comparable computed tomography and magnetic resonance imaging measurements between examinations and for research purposes. (1) Correction of tilt on the coronal plane: aligning the superior edges of the femoral heads or the inferior margins of the ischial tuberosities. (2) Correction of rotation in the axial plane: aligning both posterior acetabular wall margins or the anterosuperior iliac spines (ASIS). (3) Defining the anterior pelvic plane (APP) (correction for tilt in the sagittal plane): aligning the ASIS and the anterior edge of the pubic symphysis. The APP is thus defined by three bony landmarks, the ASIS on both sides and the pubic symphysis. The angle between the APP and the horizontal is defined as the APP angle. Perpendicular to the APP, multiple planes can be generated covering both acetabula from top to bottom. On each of these planes, the acetabular version can be determined, usually measured at the center of the femoral head (central acetabular version; Anda et al, 1986) or $5 \mathrm{~mm}$ from the acetabular roof (cranial acetabular version; Jamali et al, 2007). (4) Femoral measurements: The center of the femoral head is identified by placing a circle over the contour of the femoral head. The femoral neck axis (FNA) can be defined as a line that passes through the center of the femoral head and the center of the femoral neck at its narrowest point, although other anatomical methods may be applied (Bouma et al, 2014). For measurements of the proximal femur with neutralization of the femoral torsion, a reconstruction in the coronal plane of each hip is performed. The femoral coronal plane is defined as the plane between the FNA in the axial reconstruction and the long axis of the femur in the sagittal reconstruction. (5) Radial reformats performed along the FNA at 15- to 30degree intervals allows obtaining images for the alpha angle/offset measurement; 12 o'clock indicates the femoral superior (lateral) location (identified as corresponding to the most prominent image of the great trochanter), and 3 o'clock indicates the anterior location according to the mapping system suggested by Klenke et al (2015). 
a, $\mathbf{b}$
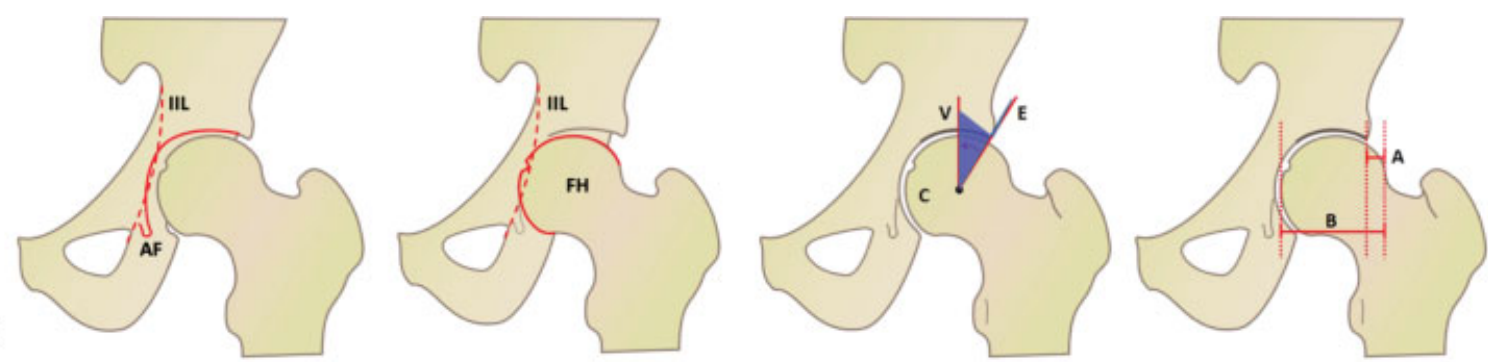

c, d
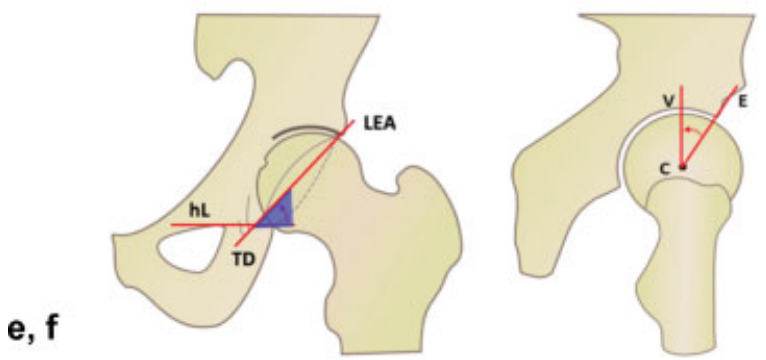

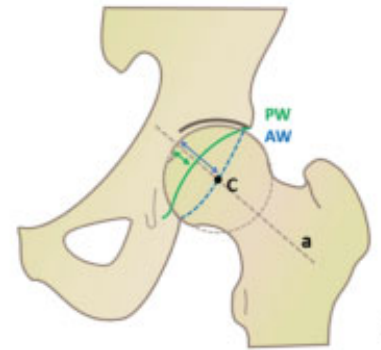

g, $\mathbf{h}$

Fig. 7 Imaging parameters to describe acetabular morphology. (a) Coxa profunda. (b) Protrusio. (c) Lateral center-edge angle. (d) Extrusion index. (e) Sharp angle. (f) Anterior center-edge angle. (g) Posterior wall sign, ischial spine sign, and crossover sign. (h) Anterior and posterior acetabular wall index. - Table 2 defines the most relevant parameters. A, extrusion in millimeters; a, neck axis; AF, acetabular fossa; AW, anterior wall; B, diameter of the femoral head; C, center; E, edge; FH, femoral head; hL, horizontal axis; IIL, ilioischial line; IS, ischial spine; LEA, lateral edge of acetabulum; PB, pelvic brim; PW, posterior wall; TD, teardrop; V, vertical.

identifying the outermost $5 \%$ of cases to define interval limits. More recently, decision limits, commonly called "cutoff values," based on outcome analysis were also introduced to aid in test interpretation. ${ }^{50}$ However, the distinction between Reflnt limits and decision limits has become blurred. ${ }^{49}$

Reflnt can be viewed in multiple ways, namely, (1) the most representative value of a parameter as defined by the mean; (2) the most commonly encountered values of such a parameter as defined by an interval (i.e., the usual $95 \%$ Reflnt); (3) parameter values associated with a clinical event/outcome; and (4) a committee's consensus of reference intervals. In radiology and orthopaedics, researchers are usually interested in "normality" in terms of definitions 2 or 3.

\section{Which Population to Study}

The reference population must be carefully defined on the basis of the intended clinical use of the underlying test. If a particular characteristic guides the definition of the reference population (e.g., nonsymptomatic and/or individuals with non-OA hips), then this population should reflect a random sampling of such individuals. But if pain and $\mathrm{OA}$ is not the underlying concern, but rather the epidemiological relationship of an individual's hip shape with the population at large, the most appropriate reference population will be made up of randomly selected individuals from the general population. Presently, interpretation of hip shape in combination with clinical information seem to represent a better way to assess the likelihood of determining a patient with $\mathrm{FAI} / \mathrm{DDH}^{4}$

Reference intervals (epidemiological use): Defined by threshold values between which the values of a specified percentage (usually $95 \%$ ) of apparently healthy individuals would fall. The threshold or limiting values for the RefInt are usually the $2.5 \%$ and $97.5 \%$ fractions of the parameter distribution in the reference population.

Reference intervals (defined by a specific clinical outcome): Whereas the 97.5 percentile (upper limit) for, for example, the $\alpha$ values in the general population lies between 70 and 77 degrees, ${ }^{51,52}$ the upper reference limits for $\alpha$ as defined by a specific clinical outcome (hip pain) would correspond to 57 to 60 degrees (which in turn corresponds approximately to the 50-75th percentile of the "epidemiological RefInt"). These values were determined having a specific clinical outcome in mind because they were associated with hip pain in specific studies. ${ }^{53}$ For FAI assessment, it is reasonable to suggest that defining Reflnt based on an asymptomatic healthy reference population may ultimately be the preferred approach.

Reference intervals (based on the genotype and/or phenotype): It is now known that the most commonly encountered values (reference values) for some parameters vary with some factors of the individual (e.g., $\alpha$ angle variation with $\operatorname{sex}^{27}$ and race $^{52}$ ). Several phenotypic/genetic markers are known to have a role in hip shape, and it is possible that yet undefined markers may influence observed Reflnt for hip parameters.

Part of the reason that population overlap has been observed in the distributions of quantitative hip parameters in asymptomatic individuals and patients with femoroacetabular impingement syndrome (FAIS) is that determination of hip impingement depends on many variables beyond the tests performed in hip imaging. Examination of any single parameter will not necessarily provide a definitive diagnosis in a given patient. A potential solution to this problem is to develop a multidimensional reference region or multivariate approaches. ${ }^{53,54}$ In fact, when quantitative parameter results for both asymptomatic and individuals with FAIS are 
Table 1 Imaging parameters to describe acetabular morphology ${ }^{\mathrm{a}}$

\begin{tabular}{|c|c|c|c|c|}
\hline Acetabulum & Parameter & Values & Imaging technique & Definition \\
\hline \multirow[t]{3}{*}{ Depth } & Coxa profunda & Positive/Negative & AP pelvis & AF touches or crosses the IIL \\
\hline & Protrusio acetabuli & Positive/Negative & AP pelvis & FH touches or crosses the IIL \\
\hline & Acetabular depth & Positive/Negative & $\begin{array}{l}\mathrm{CT} / \mathrm{MRI} \text { transverse } \\
\text { oblique image of } \\
\text { the FN long axis }\end{array}$ & $\begin{array}{l}\text { Distance between center of } \mathrm{FH} \text { and line connect- } \\
\text { ing the anterior/posterior acetabular rim. If } \leq \\
3 \mathrm{~mm} \text {, considered positive for pincer morphology } \\
\text { (Leunig et al, 2013) }\end{array}$ \\
\hline \multirow[t]{11}{*}{ Coverage } & $\begin{array}{l}\text { Lateral center-edge, } \\
\text { L-CEA }\end{array}$ & (angle) & $\begin{array}{l}\text { AP pelvis } \\
\mathrm{CT} / \mathrm{MRI}\end{array}$ & $\begin{array}{l}\text { Angle formed by a vertical line }(\mathrm{v}) \text { and a line } \\
\text { through the center of the } \mathrm{FH}(\mathrm{C}) \text { and the lateral } \\
\text { bony rim of the acetabulum }\end{array}$ \\
\hline & $\begin{array}{l}\text { Center-edge angle } \\
\text { of Wiberg, W-CEA }\end{array}$ & (angle) & AP pelvis & $\begin{array}{l}\text { Lateral end of the sourcil (i.e., the weightbearing } \\
\text { area of the acetabulum), rather than the lateral } \\
\text { rim of the acetabulum }\end{array}$ \\
\hline & $\begin{array}{l}\text { Acetabular roof } \\
\text { angle of Tönnis or } \\
\text { acetabular } \\
\text { inclination }\end{array}$ & (angle) & $\begin{array}{l}\text { AP pelvis } \\
\mathrm{CT} / \mathrm{MRI}\end{array}$ & $\begin{array}{l}\text { Angle formed by a horizontal line and a line } \\
\text { through the medial and lateral edge of the acet- } \\
\text { abular roof }\end{array}$ \\
\hline & Extrusion index & $(\%)$ & AP pelvis & $\%$ of the $\mathrm{FH}$ width not covered by the acetabulum \\
\hline & Sharp angle & (angle) & AP pelvis & $\begin{array}{l}\text { Angle between a horizontal line (hL) and a line } \\
\text { connecting the teardrop (TD) and lateral edge of } \\
\text { the acetabulum (LEA) }\end{array}$ \\
\hline & ADR & NA & AP pelvis & $\begin{array}{l}\text { The depth of the acetabulum divided by the width } \\
\text { of the acetabulum, multiplied by } 1,000 \text {, presented } \\
\text { as a ratio: }(A / B)^{*} 1,000\end{array}$ \\
\hline & $\begin{array}{l}\text { Anterior center- } \\
\text { edge }\end{array}$ & (angle) & $\begin{array}{l}\text { False profile } \\
\mathrm{CT} / \mathrm{MRI}\end{array}$ & $\begin{array}{l}\text { Angle formed by a vertical line }(\mathrm{V}) \text { and a line } \\
\text { through the center of the femoral head }(\mathrm{C}) \text { and the } \\
\text { anterior edge of the acetabulum (E) }\end{array}$ \\
\hline & Coverage & $(\%)$ & $\mathrm{CT} / \mathrm{MRI}$ & $\begin{array}{l}\text { Technique to measure the \% cover of the FH by the } \\
\text { weightbearing zone (pelvic position standardized } \\
\text { relative to a specific anatomical plane) }\end{array}$ \\
\hline & $\begin{array}{l}\text { Acetabular version } \\
(1,2 \text {, and } 3 \text { o'clock })\end{array}$ & (angle) & $\mathrm{CT} / \mathrm{MRI}$ & $\begin{array}{l}\text { Intersection of a perpendicular to the line } \\
\text { between the posterior pelvic margins and a line } \\
\text { connecting the anterior/posterior acetabular rims }\end{array}$ \\
\hline & AASA & (angle) & $\mathrm{CT} / \mathrm{MRI}$ & $\begin{array}{l}\text { Angle formed by lines through the center of the } \mathrm{FH} \\
\text { and contralateral } \mathrm{FH} \text { and tangential to the anterior } \\
\text { lip of the acetabulum }\end{array}$ \\
\hline & PASA & (angle) & $\mathrm{CT} / \mathrm{MRI}$ & $\begin{array}{l}\text { Angle formed by lines through the center of the FH } \\
\text { and contralateral FH and tangential to the pos- } \\
\text { terior acetabular lip }\end{array}$ \\
\hline \multirow[t]{5}{*}{ Orientation } & PW sign & Positive/negative & AP pelvis & $\begin{array}{l}\text { Positive if the PW runs medially to the center of } \mathrm{FH} \\
\text { (C) }\end{array}$ \\
\hline & $\mathrm{AWI}$ and $\mathrm{PWI}$ & Positive/negative & AP pelvis & $\begin{array}{l}\text { Ratio of the width of the acetabular AW/PW } \\
\text { measured along the FN axis (a) divided by the FH } \\
\text { radius ( } r \text { ) }\end{array}$ \\
\hline & Crossover sign & Positive/negative & AP pelvis & AW crosses laterally the PW \\
\hline & Retroversion index & $(\%)$ & AP pelvis & $\begin{array}{l}\% \text { of retroverted acetabular opening divided by } \\
\text { entire opening }\end{array}$ \\
\hline & Ischial spine sign & Positive/negative & AP pelvis & Positive if IS is projected medially to PB \\
\hline Others & McKibbin index & - & $\mathrm{CT} / \mathrm{MRI}$ & $\begin{array}{l}\text { Sum of femoral torsion and the acetabular version } \\
\text { (at } 3 \text { o'clock) }\end{array}$ \\
\hline
\end{tabular}

Abbreviations: AASA, anterior acetabular sector angle; ADR, acetabular depth-width ratio; AF, acetabular fossa; AP, anteroposterior; AW, anterior wall; AWI, anterior wall index; CT, computed tomography; FH, femoral head; FN, femoral neck; IIL, ilioischial line; IS, ischial spine; L-CEA, later centeredge angle; MRI, magnetic resonance imaging; NA, not applicable; PASA, posterior acetabular sector angle; PB, pelvic brim; PW, posterior wall; PWI, posterior wall index; W-CEA, Wiberg center-edge angle.

a Figure 7 shows the corresponding illustration.

available, various approaches can be used to set decision limits for these parameters by examining the test sensitivity and specificity at various test threshold settings. Such thresholds are best set by the use of receiver operating character- istic (ROC) analysis. ${ }^{50}$ Examples of studies that have used this approach for setting decision limits of tests in FAIS include those by Mascarenhas et $\mathrm{al}^{53}$ and Sutter et $\mathrm{al}^{55}$ in the hippreserving surgery field. 

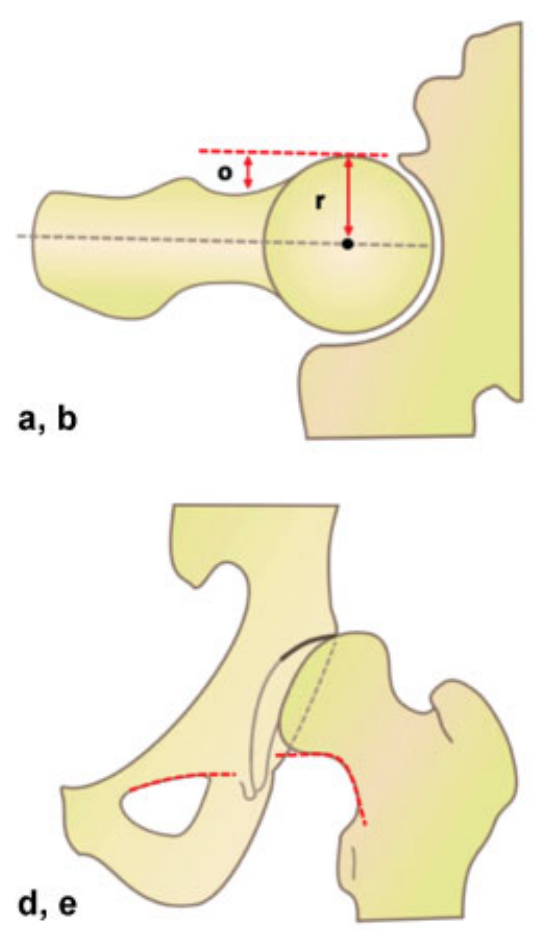
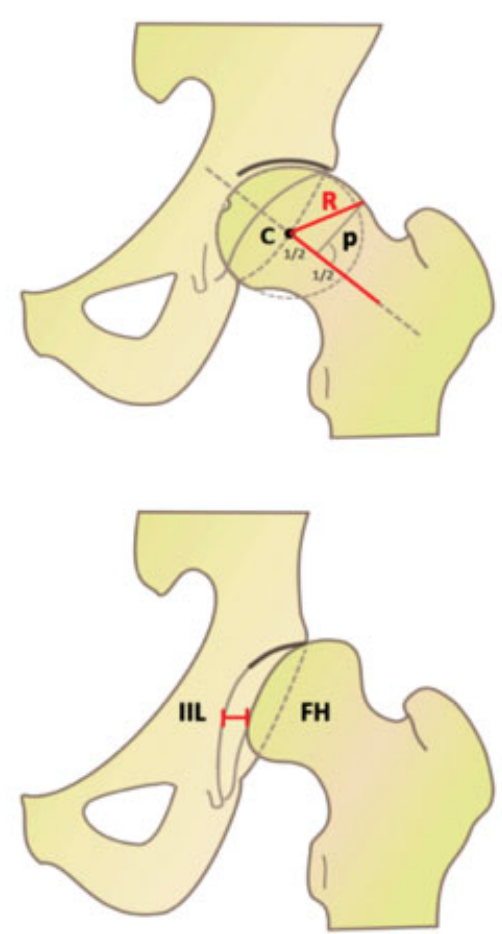
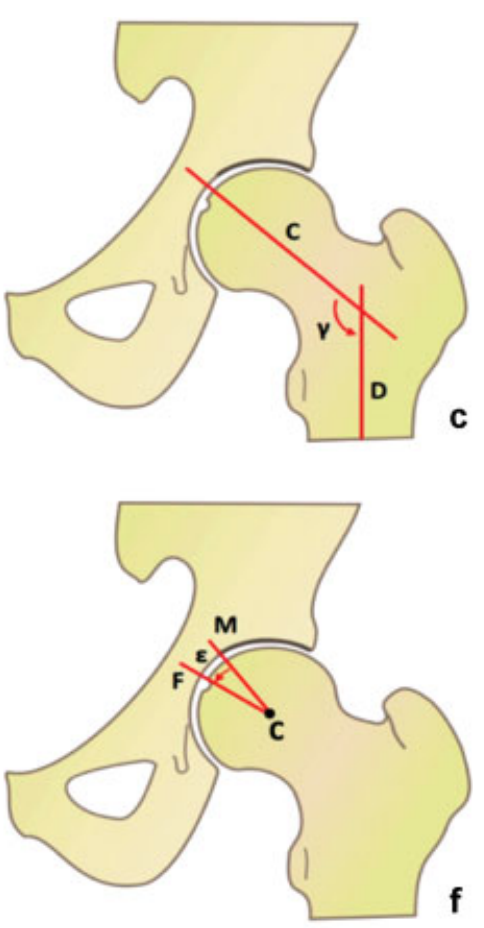

Fig. 8 Imaging parameters to describe femoral morphology. - Table 3 lists the definitions. (a) Offset and offset ratio. (b) Triangular index. (c) Centrum collum diaphyseal (CCD) angle. (d) Shenton's line. (e) Lateralization of femoral head. (f) Fovea angle delta. r, radius of the femoral head; $\mathrm{C}$, center; E, edge; FH, femoral head; IIL, ilioischial line; o, offset; F, fovea; M, medial margin of roof.

\section{Key Point}

In the setting of hip-preserving surgery, defining reference intervals based on an asymptomatic healthy reference population and defining decision limits based on a clinical outcome may ultimately be the preferred approach.

\section{Acetabular Assessments}

\section{What They Are and How to Measure Them}

The diagnostic preoperative assessment of the acetabulum is confined to the recognition of the osseous and cartilage under- and overcoverage of the femoral head and acetabular version with correlation to femoral head and neck abnormalities. ${ }^{16,53}$ In addition, imaging should visualize localized under- and overcoverage for dedicated measurements.

AP radiography of the pelvis ${ }^{9}$ provides important information concerning acetabular coverage but has a limited ability to characterize acetabular version abnormalities precisely. Signs of joint space narrowing generally considered exclusion criteria for hip-preserving surgery, can also be detected.

The W-CEA continues to be the most used measure of superolateral femoral head coverage. The most superolateral point of the sclerotic weightbearing zone of the acetabulum, the sourcil, defines the edge of the acetabulum ${ }^{56}$ (- Fig. 9).
The most superolateral osseous margin of the acetabulum is commonly used for the measurement ( - Fig. 9a), resulting in the L-CEA. ${ }^{51,57,58}$ Surprisingly, the W-CEA is often connected with Ogata et $\mathrm{al}^{59}$ and the L-CEA with Wiberg. ${ }^{56}$ However, Ogata et al $^{59}$ suggested the same measurement as described earlier by Wiberg. ${ }^{56,60}$ It is important to distinguish precisely between $\mathrm{W}$-CEA and L-CEA. ${ }^{17,59,61,62}$ The $\mathrm{W}$-CEA represents the weightbearing supero/lateral coverage and the L-CEA expresses the bony acetabular extension laterally.

The acetabular inclination (Ac-inclination), or acetabular index, ${ }^{63}$ is a commonly used supplementary measure of acetabular coverage, defined by a line connecting the lateral and medial margins of the acetabular roof/sourcil (respectively, point $\mathrm{E}$ and the superior-lateral margin of the acetabular fovea) (-Fig. 9a, b).

The A-CEA (-Fig. 7f) is measured on the oblique falseprofile standing lateral radiograph of the hip. ${ }^{9}$ This measurement requires precise and reproducible 65-degree oblique positioning of the pelvis that may be difficult to obtain and assess. ${ }^{64}$ There are several other measures of acetabular depth and coverage ( - Table 2 ), but these are less commonly used in the general therapeutic decision-making process.

The crossover sign, crossover index, posterior wall sign, and ischial spine sign ( $\mathbf{- F i g . ~} \mathbf{7 g}$ ) may serve as indicators of a reduced acetabular version or acetabular retroversion 19,65,66 but should not determine therapeutic decisions as isolated findings. Such signs are commonly present on radiographs of normal subjects, ${ }^{22,67}$ although they may be significant if clearly abnormal or several of these signs are present. Some authors consider them to be less reliable compared with CT measurements of the acetabular version. ${ }^{23,68,69}$ 


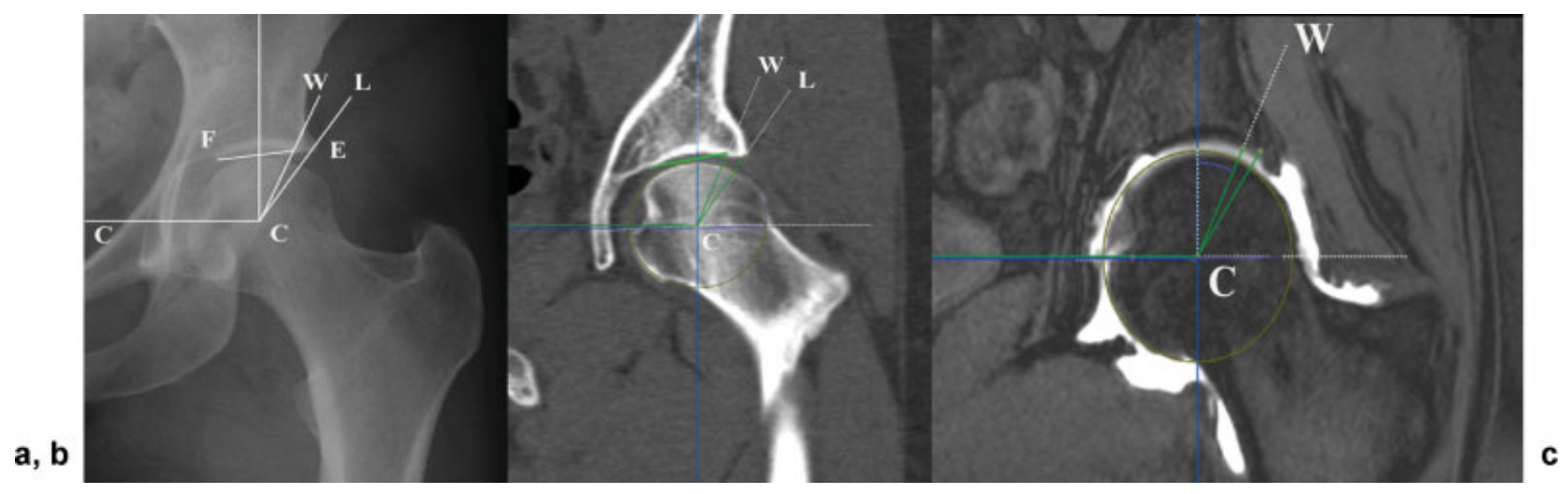

Fig. 9 Measurement of acetabular craniocaudal coverage using Wiberg center-edge angle (W-CEA), lateral center-edge angle (L-CEA), and acetabular inclination (Ac-inclination) on (a) radiographs, (b) computed tomography (CT), and (c) magnetic resonance imaging (MRI). The landmark E (Edge) on the line W-C (C is the center of the femoral head) is on radiographs (a) and CT (b) at the lateral margin of subchondral acetabular density or where the acetabulum ends laterally. On MRI, landmark E on the line W-C is at the point of transition between the cartilage and labrum. W-CEA is the angle between a line perpendicular to line CC and line W-E-C. Point $\mathrm{E}$ on the line $\mathrm{L}-\mathrm{C}$ is the lateral osseous margin of the acetabulum. L-CEA is the angle between the line perpendicular to CC and the line L-E-C. AC-inclination is the angle between the line F-E and CC. C, center of femoral head; F, fovea or medial margin of the sourcil; L, lateral edge of the acetabulum; W, sourcil/weightbearing lateral point according to Wiberg.

CT and MRI for measuring the amount of acetabular coverage (both craniocaudal and AP) and version should include volumetric data and appropriate software to secure alignment of the centers of the femoral heads in the true coronal and transverse planes ( $\mathbf{- F i g . ~ 1 0 )}$. Measurements are performed with the patient in a supine position and may not represent the functional position of the acetabulum. ${ }^{70}$ The anterior pelvic plane (APP) or pelvic tilt can be adjusted to a standardized position ${ }^{53}$ (hence facilitating reproducible measurements), which may still be different from the functional position of the pelvis. In relevant cases, pelvic inclination on a low-dose standing lateral radiograph of the pelvis can also be used for functional alignments.

Landmarks in the transverse plane are the most anterior lateral and posterior osseous margins of the acetabulum. Acetabular version (Ac-version), anterior acetabular sector angle, and posterior acetabular sector angle are measured relative to the coronal plane ${ }^{71}$ (-Fig. 10b). The landmarks in the coronal plane, superolaterally (12 o'clock), are the osseous and weightbearing margins of the acetabulum, respectively, defined as the L-CEA and W-CEA angles ${ }^{62,72}$ (-Fig. 10c). The location of point $E$ on the lateral margin of the weightbearing zone may be difficult to determine; by CT, it is located where the concave acetabular roof ends laterally ${ }^{56,61}$ or at the lateral margin of the dense subchondral bone. ${ }^{56}$ On MRI, the point of the transition between the acetabular cartilage and the labrum was suggested. ${ }^{72}$ Measurement of Ac-inclination also relies on point $\mathrm{E}$ at 12 o'clock in the coronal plane and the medial edge of the acetabulum medially. The latter landmark is frequently difficult to identify on CT and MRI (-Fig. 10, - Fig. 11).

Acetabular coverage is additionally determined by the CEA at 11:00 and 01:00 hours (h) or at $1 \mathrm{~h}$ or 30 -minute intervals from 9 to 3 o'clock by rotation of the data set in the sagittal plane around the axis between the centers of the femoral heads $5^{51,53,73,74}$ (- Fig. 11c). Both the W-CEA and
L-CEA should be measured. Center Ac-version can be measured at the center of the femoral heads ${ }^{75,76}$ (more straightforward) or at the center of the acetabulum. ${ }^{77}$ Upper Acversion can be measured either by using the $5-\mathrm{mm}$ reference distance from the acetabular roof according to Jamali et $\mathrm{al}^{78}$ or by using the line connecting the points of the osseous landmarks/the margins of the acetabulum at 11:00 and 01:00 h (-Fig. 11). This upper Ac-version measurement corresponds to the upper one fifth of the acetabular radius in the sagittal plane. The points of measurement are well defined compared with direct measurement of upper version on transverse slices that are commonly flawed due to partial volume.

The measures of acetabular coverage can finally be confirmed visually by assessing 3D surface reconstructions.

\section{Thresholds}

The epidemiological reference intervals of CEA measurements were assessed in three large population-based studies (epidemiological Refint) ${ }^{57,58,79}$ ( - Table 3). The values of the originally described W-CEA measurement according to Wiberg ${ }^{56}$ were only reported by Laborie et al. ${ }^{17}$ The difference of 2 to 3 degrees between W-CEA and L-CEA was not further analyzed by Laborie et al. ${ }^{17}$ However, other studies have emphasized much larger differences, particularly in dysplastic hips. ${ }^{59,61,62}$ L-CEA $<25$ degrees is observed in up to $20 \%$ of the population, and $25 \%$ may be classified as having dysplastic hips when using cutoff values of 25 degrees for the W-CEA. ${ }^{80}$ Therefore, a cutoff of 15 degrees for the W-CEA is suggested most relevant for diagnosing definitely pathologic dysplastic hips, with values of 15 to 20 degrees indicating less severe dysplasia. ${ }^{81}$ However, localized deficient coverage, increased Ac-inclination, and abnormal Ac-version may influence these ranges.

In the setting of FAI, both W-CEA and L-CEA should be measured and assessed, and the osseous margins 
Table 2 Imaging parameters to describe femoral morphology ${ }^{a}$

\begin{tabular}{|c|c|c|c|c|}
\hline Femur and joint & Parameter & Unit & Imaging technique & Definition \\
\hline \multirow[t]{9}{*}{ Femur sphericity } & Alpha (beta) angle & (angle) & $\begin{array}{l}\text { Axial and AP pelvis } \\
\mathrm{CT} \text { and } \mathrm{MRI}\end{array}$ & $\begin{array}{l}\text { Angle formed by FHN axis and line through center } \\
\text { of the femoral head and point where the anterior } \\
\text { (posterior) FHN contour exceeds head radius }\end{array}$ \\
\hline & Pistol-grip deformity & Qualitative & Axial and AP pelvis & $\begin{array}{l}\text { Seen as bump at FHN junction other than } \\
\text { osteophytes }\end{array}$ \\
\hline & $\begin{array}{l}\text { Flattening of lateral } \\
\text { aspect of femoral } \\
\text { head }\end{array}$ & Qualitative & $\begin{array}{l}\text { Axial and } \mathrm{AP} \text { pelvis } \\
\mathrm{CT} \text { and } \mathrm{MRI}\end{array}$ & $\begin{array}{l}\text { Flattening of normal concavity of the FHN } \\
\text { junction }\end{array}$ \\
\hline & Asphericity & Qualitative & Axial and AP pelvis & $\begin{array}{l}\text { The head is said to be aspherical if femoral epi- } \\
\text { physis extended }>2 \mathrm{~mm} \text { outside the reference } \\
\text { circle corresponding to a spherical head }\end{array}$ \\
\hline & Gamma (delta) angle & (angle) & AP pelvis & $\begin{array}{l}\text { Angle formed by FHN axis (a) and line through } \\
\text { center of the FH (C) and the point where the } \\
\text { cranial (caudal) FHN contour exceeds the head } \\
\text { radius }\end{array}$ \\
\hline & Offset & {$[\mathrm{mm}]$} & $\begin{array}{l}\text { Axial and AP pelvis } \\
\mathrm{CT} \text { and MRI }\end{array}$ & $\begin{array}{l}\text { Difference }(0) \text { between } \mathrm{FH} \text { radius }(r) \text { and neck } \\
\text { radius }\end{array}$ \\
\hline & Offset ratio & NA & $\begin{array}{l}\text { Axial and AP pelvis } \\
\mathrm{CT} \text { and MRI }\end{array}$ & Ratio of offset (o) to the $\mathrm{FH}$ radius ( $\mathrm{r}$ ). \\
\hline & Femoral distance & {$[\mathrm{mm}]$} & $\begin{array}{l}\text { Axial and AP pelvis } \\
\mathrm{CT} \text { and } \mathrm{MRI}\end{array}$ & $\begin{array}{l}\text { Perpendicular distance between a tangent along } \\
\text { anterior cortex of the FN and point of largest } \\
\text { osseous deformity at the FHN junction }\end{array}$ \\
\hline & Triangular index & NA & AP pelvis & $\begin{array}{l}\text { Perpendicular line }(p) \text { is drawn at half the head } \\
\text { radius }(r) \text {. Distance }(R) \text { is measured from the FH } \\
\text { center }(C) \text { to the point where } p \text { intersects the } \\
\text { anterior FHN contour. }\end{array}$ \\
\hline \multirow[t]{2}{*}{ Joint congruency } & Shenton's line & (Intact/Interrupted) & AP pelvis & $\begin{array}{l}\text { Interrupted if the caudal FHN contour and superior } \\
\text { border of the obturator foramen do not form a } \\
\text { harmonic arc }\end{array}$ \\
\hline & $\begin{array}{l}\text { Lateralization of } \\
\text { femoral head or posi- } \\
\text { tion of the hip center }\end{array}$ & $(\mathrm{mm})$ & AP pelvis & $\begin{array}{l}\text { Shortest distance between medial aspect of FH } \\
\text { and ilioischial line (IIL). } \\
\text { Lateralized if }>10 \mathrm{~mm}\end{array}$ \\
\hline \multirow[t]{4}{*}{ Additional findings } & $\begin{array}{l}\text { Cervicodiaphyseal } \\
\text { angle }\end{array}$ & (angle) & $\begin{array}{l}\text { AP pelvis } \\
\mathrm{CT} / \mathrm{MRI}\end{array}$ & $\begin{array}{l}\text { Angle formed by FHN axis (C) and femoral shaft } \\
\text { axis (D) }\end{array}$ \\
\hline & Fovea angle delta & (angle) & AP pelvis & $\begin{array}{l}\text { Angle formed by a line through the medial edge of } \\
\text { the acetabular roof }(M) \text { and the center of the } F H \\
\text { (C) and a line through the lateral border of the } \\
\text { fovea capitis }(F) \text { and }(C) \text {. An angle } \leq 10 \text { degrees is } \\
\text { associated with DDH }\end{array}$ \\
\hline & Joint space width & $(\mathrm{mm})$ & AP pelvis standing & Measured at point of narrowest joint space width \\
\hline & Femoral torsion & (angle) & $\begin{array}{l}\text { Transverse images } \\
\text { over proximal and } \\
\text { distal femur (CT, } \\
\text { MRI, or Dunn } \\
\text { 90 degrees) }\end{array}$ & $\begin{array}{l}\text { Angle between the long axis of the FN and tangent } \\
\text { at the condyles of the distal femur }\end{array}$ \\
\hline
\end{tabular}

Abbreviations: AP, anteroposterior; CT, computed tomography; DDH, developmental dysplasia of the hip; FH, femoral head; FHN, femoral headneck; FN, femoral neck; MRI, magnetic resonance imaging; NA, not applicable.

a - Figure 8 shows the corresponding illustration.

corresponding to L-CEA may, in cases of overcoverage, be the most valuable from a preservation treatment perspective. ${ }^{51,61}$ The reference values of W-CEA, L-CEA, and Ac-index with respect to overcoverage appear in - Table 4. However, L-CEA RefInt are wide, and values of 23 to 33 degrees were suggested. ${ }^{48}$ All global and localized measures of overcoverage should be assessed in relation to femoral and pelvic parameters. $^{53}$

\section{Acetabular Inclination}

The Reflnt and cutoff values for Ac-inclination were determined in large population-based cohorts evaluated by XR with mean values of 3.8 to 5.6 degrees (95\% RefInt: -7 to 15 degrees), in large asymptomatic cohorts evaluated by $\mathrm{CT}^{51}$ with mean values of $3.4 \pm 5.4$ degrees (95\% Reflnt: -8 to 14 degrees), and by MRI with mean values of $2.9 \pm 5.4$ degrees (95\% RefInt: -8 to 14 degrees). ${ }^{53}$

Recently, a decision limit threshold of 6 degrees was suggested (sensitivity 65\%, specificity $70 \%$; area under the curve [AUC]: 0.709) to predict a symptomatic hip (with decreasing superior acetabular coverage; i.e., by increasing Ac-inclination, more symptomatic hips were found). In fact, likelihood of symptomatic disease doubled with a 7-degree Ac-inclination increase. ${ }^{53}$ 


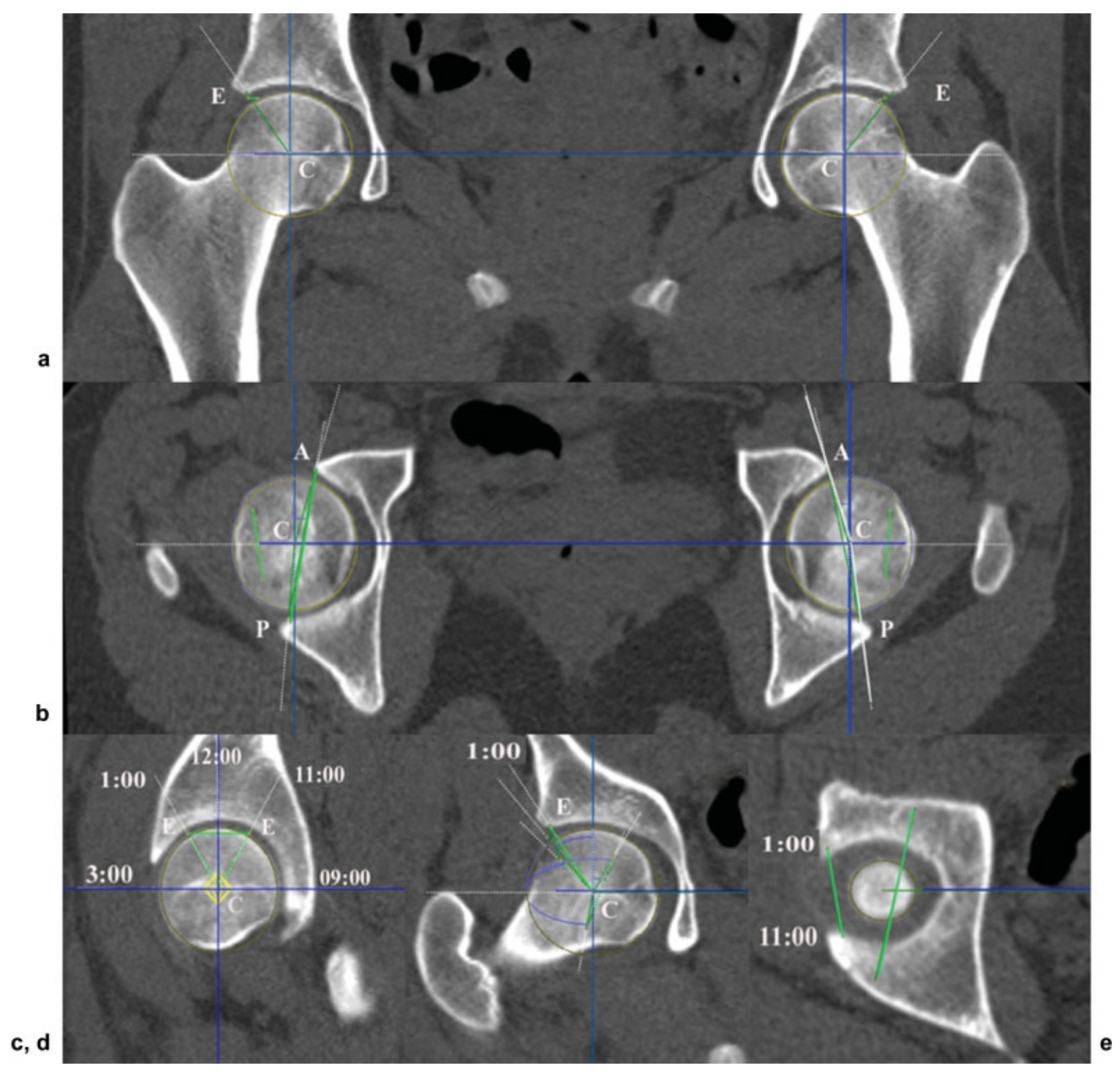

Fig. 10 Measurements of acetabular parameters on multiplanar computed tomography (CT) reconstructions. The centers (C) of the right and left femoral head are obtained by the best fit of multiple points on the osseous surface of the femoral head in three planes (a, b, and $c$ ). The line joining the centers of femoral heads is aligned into the coronal and axial plane. (a) W-CEA at 12:00 h is the angle between line CE and a line perpendicular to line CC. (b) Point A and $P$ is the anterolateral and posterolateral margin of the concave acetabular joint surface in the horizontal plane. The mid-transversal acetabular version (Acversion) is the anterior angle between line A-P and a line perpendicular to the line CC. The anterior acetabular sector angle (AASA or CEA; 3:00 h) is the medial angle between line A-C and C-C (anterior white line). The posterior acetabular sector angle (PASA or CEA; 9:00 h) is the medial angle between line C-P and C-C (posterior white line). (c) Sagittal slice through the center of the femoral head. (d) CEA measurement in the oblique coronal plane at 1:00 h. The oblique coronal plane is determined by the line CC and CE (11:00 h) as in (a). A similar measurement is performed at 11:00 $\mathrm{h}$ (not shown). A line is drawn between point $E$ at 1:00 and 11:00 h to obtain the cranial acetabular version shown as the short green line on (e). There is retroversion superiorly. For comparison the Ac-version at mid-transversal level is displayed as a long green line corresponding to the line shown on (b). A, anterior; C, center of femoral head; E, edge; I, inferior; P, posterior; S, superior.

\section{Acetabular Version}

The RefInt and cutoff values for center Ac-version (the midaxial slice through the center of the femoral heads) were determined in large asymptomatic cohorts ${ }^{51,53}$ with mean values of $21 \pm 5$ degrees (95\% RefInt: 12-31 degrees; 4-5 degrees higher in females). Similar findings were seen in other studies using XR, ${ }^{63,77} \mathrm{CT},{ }^{82-84}$ and MRI. ${ }^{53}$

Landmarks for measuring Ac-version in the upper hemisphere have rarely been defined in the literature, probably because this part of the acetabulum is often purely defined in the horizontal plane, but mild retroversion is common. ${ }^{22,85}$ Differences between the 11:30/ 01:30 $\mathrm{h}$ and 11:00/01:00 h L-CEAs may represent a more appropriate measure of the upper Ac-version, but reference values are not widely available. Jamali et al proposed measuring the cranial version at $5 \mathrm{~mm}$ from the acetabular roof, which may be regarded as a more practical approach. 


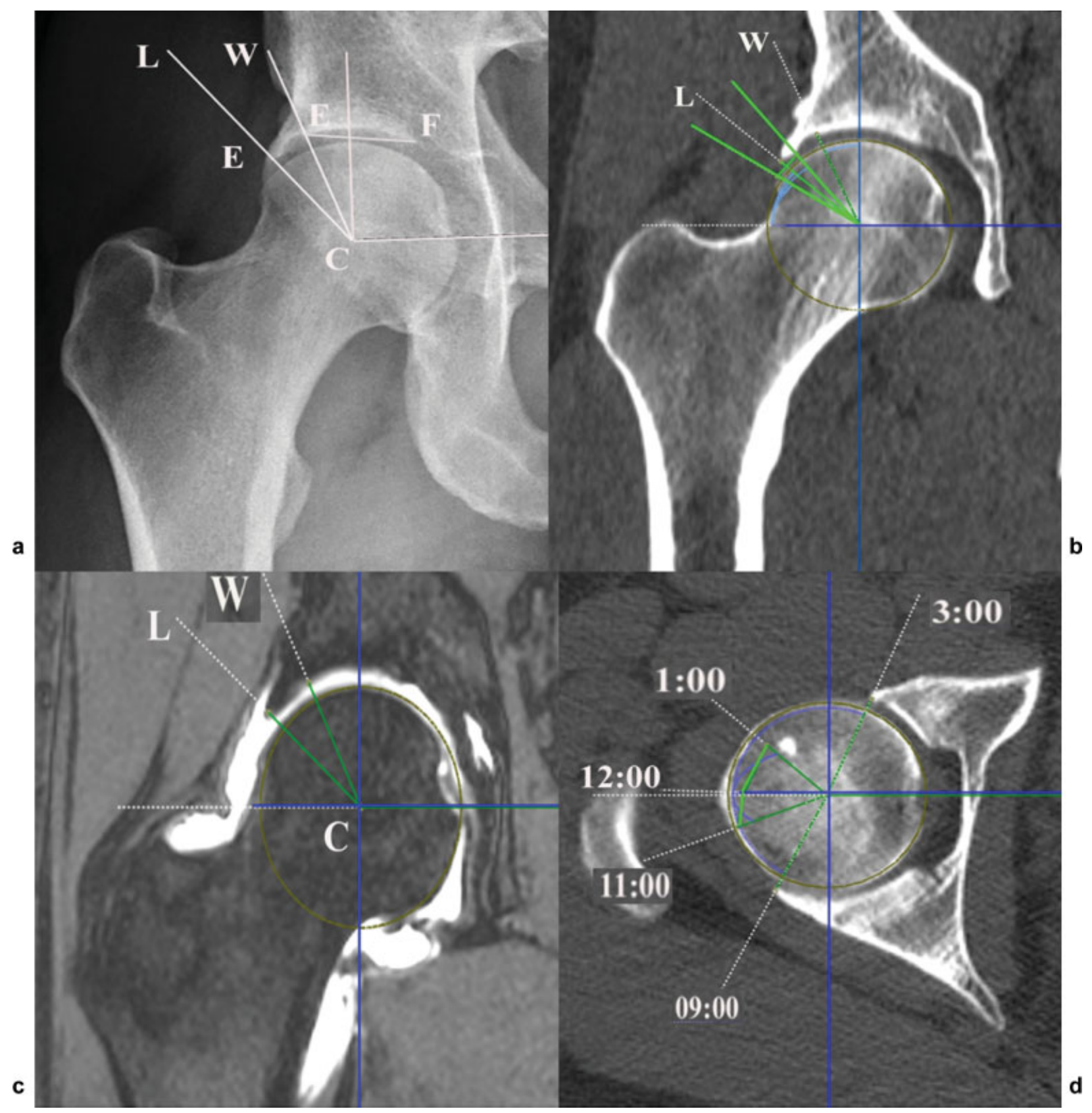

Fig. 11 Acetabular measurements in femoroacetabular impingement (FAI) and pincer. (a) Radiography, (b) coronal computed tomography (CT) reconstruction, and (c) coronal reconstruction of 3D T1 fat-saturated magnetic resonance arthrography of the right hip in a 29-year-old woman with hip pain. Wiberg center-edge angle and lateral center-edge angle (L-CEA) is 23 and 41 degrees, respectively, by radiography that are confirmed on CT (b) and MRI (c). The upper and lower green lines on (b) represent the L-CEA measurements at 1:00 and 11:00 h, respectively. Note that it may be difficult on most MR sequences to differentiate between a normal and an ossified labrum. (d) Axial CT reconstruction showing the 11:00-12:00-1:00 h upper acetabular coverage projected (short green lines) on the central axial section. C, center of femoral head; $E$, acetabular edge (sourcil edge and lateral osseous edge, respectively); E-F line, acetabular inclination; F, fovea or medial margin of the sourcil; L, lateral edge of the acetabulum; W, Sourcil/weightbearing lateral point according to Wiberg.

\section{Key Points}

1. CEA, Ac-inclination, and Ac-version are the most important parameters to define acetabular morphology.

2. Precise definition of whether the L-CEA or W-CEA is used is paramount.

\section{Femoral}

\section{The $\alpha$ Angle}

\section{General Considerations}

The quantitative parameter most widely used to evaluate camtype morphology is the $\alpha$ angle ${ }^{86}$ because it represents the degree of asphericity of the FHN junction (-Fig. 12). The original method (method 1 of Nötzli et al $^{86}$ ) was described in an axial oblique arthro-MRI image and is commonly known as 
Table 3 Reference intervals of acetabular measurements obtained in selected population-based studies ${ }^{\mathrm{a}}$ and asymptomatic populations $^{\mathrm{b}}$

\begin{tabular}{|c|c|c|c|c|c|c|c|c|}
\hline Measurement & Study & Sex & $N$ & Modality & Age, y & $\begin{array}{l}2.5 \\
\text { percentile }\end{array}$ & $\begin{array}{l}\text { Mean, } \\
\text { degrees }\end{array}$ & $\begin{array}{l}97.5 \\
\text { percentile }\end{array}$ \\
\hline \multirow[t]{2}{*}{ W-CEA } & \multirow{2}{*}{$\begin{array}{l}\text { Laborie et al, } \\
2013^{17 a}\end{array}$} & $\mathrm{M}$ & 841 & CR & 19 & 18.4 & 35 & 42.8 \\
\hline & & $\mathrm{F}$ & 1,170 & $C R$ & 19 & 17.1 & 35 & 42.0 \\
\hline \multirow[t]{2}{*}{ L-CEA } & \multirow{2}{*}{$\begin{array}{l}\text { Laborie et al, } \\
2013^{17^{a}}\end{array}$} & $M$ & 841 & $C R$ & 19 & 20.8 & 32.1 & 45.0 \\
\hline & & $\mathrm{F}$ & 1,170 & $C R$ & 19 & 19.6 & 31.0 & 43.4 \\
\hline \multirow[t]{2}{*}{ L-CEA } & \multirow{2}{*}{$\begin{array}{l}\text { Werner et al, } \\
2012^{57^{a}}\end{array}$} & $\mathrm{M}$ & 871 & CR & $14-97$ & 18.0 & 34.5 & 47.0 \\
\hline & & $\mathrm{F}$ & 355 & $C R$ & $14-97$ & 18.0 & 33.2 & 48.4 \\
\hline \multirow[t]{2}{*}{ L-CEA } & \multirow{2}{*}{$\begin{array}{l}\text { Fischer et al, } \\
2018^{58^{a}}\end{array}$} & $\mathrm{M}$ & 1,587 & MR & $21-90$ & 17 & 30 & 44 \\
\hline & & $\mathrm{F}$ & 1,639 & MR & $21-88$ & 18 & 32 & 45 \\
\hline \multirow[t]{2}{*}{ L-CEA } & \multirow{2}{*}{$\begin{array}{l}\text { Mascarenhas } \\
\text { et al, } 2018^{51^{b}}\end{array}$} & $\mathrm{M}$ & 271 & $\mathrm{CT}$ & $14-45$ & 20 & 35.8 & 47 \\
\hline & & $\mathrm{F}$ & 319 & $\mathrm{CT}$ & $14-45$ & 22 & 34.4 & 45 \\
\hline \multirow[t]{2}{*}{ L-CEA } & \multirow{2}{*}{$\begin{array}{l}\text { Mascarenhas } \\
\text { et al, } 2018^{53^{b}}\end{array}$} & $\mathrm{M}$ & 186 & MR & $17-50$ & 20 & 36.4 & 48 \\
\hline & & $\mathrm{F}$ & 186 & MR & $16-50$ & 20 & 35.2 & 49 \\
\hline \multirow[t]{2}{*}{ Ac-inclination } & \multirow{2}{*}{$\begin{array}{l}\text { Laborie et al, } \\
2013^{17^{\mathrm{a}}}\end{array}$} & $M$ & 841 & $C R$ & 19 & -4.7 & 5.6 & 14.8 \\
\hline & & $\mathrm{F}$ & 1,170 & CR & 19 & -4.1 & 5.8 & 15.6 \\
\hline \multirow[t]{2}{*}{ Ac-inclination } & \multirow{2}{*}{$\begin{array}{l}\text { Werner et al, } \\
2012^{57^{a}}\end{array}$} & $\mathrm{M}$ & 871 & $C R$ & $14-97$ & -6.1 & 4.7 & 15.3 \\
\hline & & $\mathrm{F}$ & 355 & CR & $14-97$ & -7.5 & 3.8 & 14.5 \\
\hline \multirow[t]{2}{*}{ Ac-inclination } & \multirow{2}{*}{$\begin{array}{l}\text { Mascarenhas } \\
\text { et al, } 2018^{51^{b}}\end{array}$} & $\mathrm{M}$ & 271 & $\mathrm{CT}$ & $14-45$ & -9 & 2.4 & 14 \\
\hline & & $\mathrm{F}$ & 319 & $\mathrm{CT}$ & $14-45$ & -6 & 4 & 13 \\
\hline \multirow[t]{2}{*}{ Ac-inclination } & \multirow{2}{*}{$\begin{array}{l}\text { Mascarenhas } \\
\text { et al, } 2018^{53^{b}}\end{array}$} & $M$ & 186 & MR & $16-50$ & -8 & 2 & 12 \\
\hline & & $\mathrm{F}$ & 186 & MR & $16-50$ & -6 & 3.7 & 14 \\
\hline \multirow[t]{2}{*}{ Ac-version } & \multirow{2}{*}{$\begin{array}{l}\text { Mascarenhas } \\
\text { et al, } 2018^{51^{b}}\end{array}$} & $\mathrm{M}$ & 271 & $\mathrm{CT}$ & $14-45$ & 8 & 18.2 & 27 \\
\hline & & $\mathrm{F}$ & 319 & $\mathrm{CT}$ & $14-45$ & 14 & 22.9 & 32 \\
\hline \multirow[t]{2}{*}{ Ac-version } & \multirow{2}{*}{$\begin{array}{l}\text { Mascarenhas } \\
\text { et al, } 2018^{53^{b}}\end{array}$} & $\mathrm{M}$ & 186 & MR & $16-50$ & 7 & 17.8 & 28 \\
\hline & & $\mathrm{F}$ & 186 & MR & $16-50$ & 13 & 23.6 & 33 \\
\hline
\end{tabular}

Abbreviations: Ac-inclination, acetabular inclination or index; CR, conventional radiography of the pelvis including both hips; CT, computed tomography; $\mathrm{F}$, female; L-CEA, lateral center-edge angle; M, male; MR, MRI of the pelvis including both hips; W-CEA, weightbearing center-edge angle of Wiberg. aPopulation-based-studies.

${ }^{\mathrm{b}}$ Asymptomatic cohort.

the "three-point method" (uses one single point to construct the neck axis). Another method known as the "anatomical method" (later described by Bouma et $\mathrm{al}^{87}$ ) uses multiple points to define the femoral neck axis (FNA) and attempts to define the true anatomical axis. Depending on the method used, the $\alpha$ angle may or may not account for other morphological characteristics such as head-neck offset. In both, the $\alpha$ angle measurement requires identification of the FNA.

The main limitations of the $\alpha$ angle are (1) only moderate reproducibility, ${ }^{88}(2)$ incomplete quantification of cam morphology ${ }^{89}$; and (3) suboptimal accuracy in distinguishing patients with FAIS from healthy individuals (due to substantial overlap in $\alpha$ angle measurements between these groups). ${ }^{55}$ This further emphasizes that the radial analysis of the FHN junction is paramount, and perhaps in conjunction with 3D models, it is able to provide clinicians with another perspective to analyze a femoral deformity. ${ }^{27}$

The most common position in which the largest $\alpha$ angle and raised $\alpha$ angle are found coincides with 1 and 1:30 o'clock on the clock face. ${ }^{27,52}$ In fact, in asymptomatic individuals, the maximum mean $\alpha$ angle is most commonly located anterosuperiorly at 1:14 to $1: 36$ o'clock. $^{51,52}$

Factors such as race ${ }^{52}$ and sex ${ }^{27,51,90}$ definitely influence $\alpha$ angle values (higher $\alpha$ angles are expected in males and also in whites compared with Africans and finally Asians). Yanke et $\mathrm{al}^{90}$ and Mascarenhas et $\mathrm{al}^{27}$ found that men have larger cam radial extension, higher maximal mean increased $\alpha$ angle, and epicenter superiorly located in the anterosuperior quadrant (1 versus 1:30 o'clock). As such it is important to recognize that the plane of measurement greatly influences the $\alpha$ angle ${ }^{51,53}$ (- Fig. 13).

Two systematic reviews ${ }^{5,91}$ reported that the prevalence of an asymptomatic cam morphology ranges from 7\% to $100 \%$ (mean: $22.4 \pm 6.2 \%)^{5}$ The mean $\alpha$ angle in those asymptomatic hips was, respectively, 47 degrees $( \pm 2.0 \text { degrees })^{5}$ and 54.1 degrees $( \pm 5.1 \text { degrees })^{91}$ (irrespective of the imaging method or measurement location around the femoral head). In contrast, in asymptomatic cohorts evaluated with 3D CT, a 
Imaging Methodology for Hip Preservation Mascarenhas et al. 213

Table 4 Reference intervals of $\alpha$ angle measurements obtained in selected population-based studies ${ }^{\text {a }}$ and asymptomatic populations $^{b}$

\begin{tabular}{|c|c|c|c|c|c|c|c|}
\hline Study & Population & $N$ & Modality & Age, y & $\begin{array}{l}\text { Mean, } \\
\text { degree }\end{array}$ & $\begin{array}{l}97.5 \\
\text { percentile }\end{array}$ & SD \\
\hline \multirow[t]{3}{*}{ Gosvig et al, $2007^{a}$} & Healthy adults & 3,202 & $\begin{array}{l}\text { CR (AP } \\
\text { pelvis) }\end{array}$ & 64 & & & \\
\hline & $\mathrm{M}$ & 1,184 & & $22-90$ & 53.2 & & 12.1 \\
\hline & $\mathrm{F}$ & 2,018 & & $23-89$ & 45.5 & & 5.4 \\
\hline \multirow[t]{3}{*}{$\begin{array}{l}\text { Laborie et al, } \\
2014^{\mathrm{a}}\end{array}$} & Random & 2,005 & $\begin{array}{l}\text { CR (AP, } \\
\text { frog-lateral }\end{array}$ & $\begin{array}{l}18.6 \\
(17.2-20.1)\end{array}$ & & & \\
\hline & $\mathrm{M}$ & 837 & $\mathrm{AP} / \mathrm{FL}$ & & $62 / 47$ & $93 / 68$ & \\
\hline & $\mathrm{F}$ & 1,168 & $\mathrm{AP} / \mathrm{FL}$ & & $52 / 42$ & $94 / 56$ & \\
\hline \multirow[t]{3}{*}{$\begin{array}{l}\text { Pollard et al, } \\
2010^{\mathrm{b}}\end{array}$} & Asymptomatic & 83 & $\begin{array}{l}\text { CR (cross- } \\
\text { table) }\end{array}$ & 46 & 47 & 62 & 8 \\
\hline & M & 39 & & 48 & 48 & 64 & 8 \\
\hline & $\mathrm{F}$ & 44 & & 44 & 47 & 62 & 8 \\
\hline \multirow[t]{3}{*}{ Hack et al, $2010^{b}$} & Asymptomatic & 400 & $\begin{array}{l}\text { MRI }(3: 00 / \\
1: 30)\end{array}$ & $\begin{array}{l}29 \\
(21.4-50.6)\end{array}$ & $40.8 / 50.1$ & & $7 / 8.1$ \\
\hline & M & 178 & & & $44 / 54$ & & $7.8 / 8.5$ \\
\hline & $\mathrm{F}$ & 222 & & & $38.1 / 47$ & & $5 / 6.1$ \\
\hline \multirow[t]{3}{*}{ Fraitzl et al, $2013^{b}$} & Random & 339 & $\begin{array}{l}\text { CR (AP, } \\
\text { frog-lateral }\end{array}$ & 47 & & & \\
\hline & $\mathrm{M}$ & 170 & $\mathrm{AP} / \mathrm{FL}$ & 47 & $49.4 / 49.1$ & 70 & 10.5 \\
\hline & $\mathrm{F}$ & 169 & $\mathrm{AP} / \mathrm{FL}$ & 55 & $45 / 46.1$ & $61 / 66$ & 8/9.9 \\
\hline \multirow[t]{3}{*}{$\begin{array}{l}\text { Scheidt et al, } \\
2014^{\mathrm{b}}\end{array}$} & Asymptomatic & 164 & $\begin{array}{l}\text { CR (Dunn } \\
45 \text { degrees) }\end{array}$ & 50.4 & 45.1 & & 8.6 \\
\hline & $\mathrm{M}$ & 56 & & & 47.5 & & \\
\hline & $\mathrm{F}$ & 108 & & & 43.8 & & \\
\hline \multirow[t]{3}{*}{$\begin{array}{l}\text { Lepage-Saucier } \\
\text { et al, } 2014^{\mathrm{b}}\end{array}$} & Asymptomatic & 188 & $\begin{array}{l}\text { CT (axial/ } \\
\text { radial 1:30) }\end{array}$ & 63.2 & $51 / 59$ & & $9 / 13$ \\
\hline & $\mathrm{M}$ & 98 & & & $50 / 59$ & $68 / 83$ & $9 / 12$ \\
\hline & $\mathrm{F}$ & 90 & & & $50 / 58$ & $69 / 82$ & $9 / 13$ \\
\hline \multirow[t]{3}{*}{$\begin{array}{l}\text { Mascarenhas et al, } \\
2017^{b}\end{array}$} & Asymptomatic & 188 & $\begin{array}{l}\text { CT 3D } \\
(3: 00 / 1: 30)\end{array}$ & $18-48$ & $46 / 59$ & $56 / 72$ & $4.9 / 6.8$ \\
\hline & $\mathrm{M}$ & 98 & & 35 & $46 / 62$ & $56 / 75$ & \\
\hline & $\mathrm{F}$ & 90 & & 34.4 & $46 / 56$ & $56 / 69$ & \\
\hline \multirow[t]{3}{*}{$\begin{array}{l}\text { Mascarenhas et al, } \\
2018^{b}\end{array}$} & Asymptomatic & 590 & $\begin{array}{l}\text { CT 3D } \\
(3: 00 / 1: 30)\end{array}$ & $14-45$ & $46 / 58$ & $58 / 70$ & $5.8 / 6.5$ \\
\hline & $M$ & 271 & & $14-45$ & $46 / 60$ & $63 / 71$ & $5.9(6.5$ \\
\hline & $\mathrm{F}$ & 319 & & $14-45$ & $46 / 56$ & $57 / 70$ & $5.7 / 5.9$ \\
\hline \multirow[t]{3}{*}{$\begin{array}{l}\text { Mascarenhas et al, } \\
2018^{\mathrm{b}}\end{array}$} & Asymptomatic & 372 & $\begin{array}{l}\text { MR 3D } \\
(3: 00 / 1: 30)\end{array}$ & $33.9 \pm 8$ & $46 / 56.6$ & $57 / 70.5$ & $5.8 / 7.1$ \\
\hline & $\mathrm{M}$ & 186 & & $17-50$ & $44.9 / 59.4$ & $56 / 73.5$ & $5.7 / 7.2$ \\
\hline & $\mathrm{F}$ & 186 & & $17-50$ & $45.3 / 54$ & $57 / 66$ & $5.8 / 6.1$ \\
\hline $\begin{array}{l}\text { Gollwitzer et al, } \\
2018^{\mathrm{a}}\end{array}$ & Random & 1,312 & $\begin{array}{l}\text { CT 3D } \\
(1: 30)\end{array}$ & 61.2 & 59 & & 9.4 \\
\hline
\end{tabular}

Abbreviations: 3D, three-dimensional; CR, conventional radiography of the pelvis, including both hips; CT, computed tomography; F, female; FL, frog-leg lateral; M, male; MR, MRI of the pelvis including both hips; SD, standard deviation.

aPopulation-based studies.

${ }^{\mathrm{b}}$ Asymptomatic cohort. 


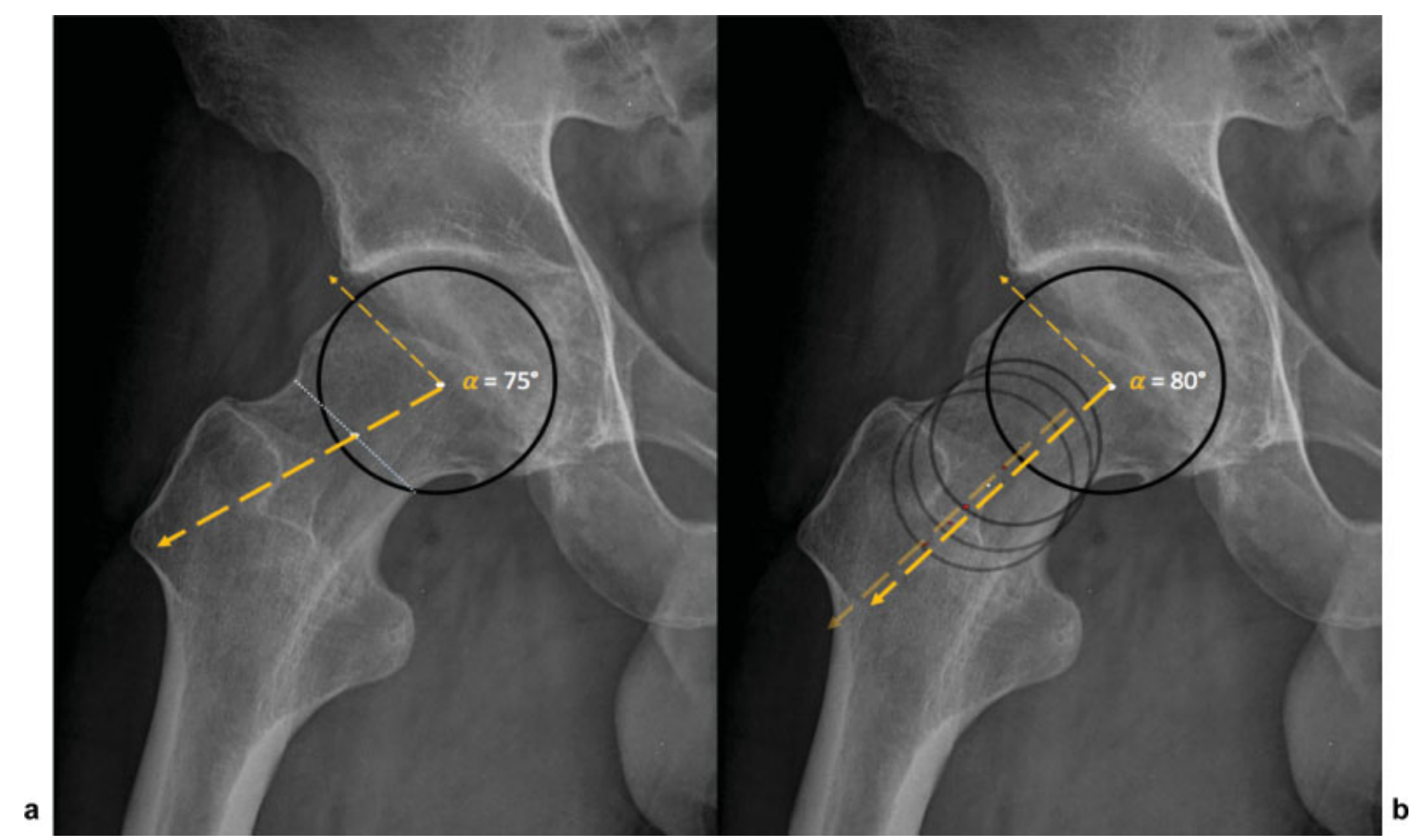

Fig. 12 Dunn 45-degree lateral view of the right proximal femur of a 35-year-old man. (a) "3-point method" or method 1 described by Nötzli et al: Place a circle adjusted over the contour of the femoral head. The axis of the neck is defined as a line passing through the femoral head center (FHC) and the femoral neck center at its narrowest point (i.e., place a circle [not shown] with its corresponding diameter (dotted line) at the shortest possible distance between the anterior (ventral) and posterior (dorsal) outline of the femoral neck). Next, a line is drawn connecting the center of these two circles. Then a line is drawn connecting the FHC to the point where the contour of the femoral head or head-neck junction first exited the femoral head circle. The $\alpha$ angle is then measured as the angle between these two lines. (b) "Anatomical method": First the femoral neck axis is determined by placing three circles, touching the contour of the neck. The middle circle is the same as the 3-point circle as just described. The two remaining circles are placed on either side of the first circle as distant as possible while ensuring that the center of these circles are still placed on the neck. Then, a line is drawn as a best fit through the centers of these circles. When the axis is confirmed, a best fit circle is placed over the femoral head and a line connecting the FHC to the point where the femoral head contour exited the femoral head circle (i.e., the alpha angle was assessed in an identical manner to the 3-point method).

higher prevalence of cam morphology was found, reaching $79 \%$ for a 55 -degree $\alpha$ angle and 33\% for a 60-degree $\alpha$ angle threshold, respectively. ${ }^{27,51}$

\section{Key Points}

1. Quantitative 3D morphometric assessment allows a thorough and reproducible hip morphology diagnosis and monitoring.

2. Cam and $\alpha$ angles/thresholds should be defined according to sex and location around the FHN.

3. Cam prevalence, magnitude, location, and epicenter differ significantly by sex.

\section{Thresholds}

Nötzli at al described the $\alpha$ angle and established that impingement was associated with a value $>55$ degrees (oblique axial MRI plane). Later on, other authors referenced 50 degrees $^{19}$ (oblique axial MRI plane) and 50.5 degrees $^{92}$ as indicators of a cam morphology. Changes used on imaging views to observe the $\alpha$ angle in different radiographic planes and multiple radial positions ${ }^{89,92,93}$ around the clock face not only improved the assessment of the cam morphology but also provoked more confusion and discussion regarding RefInt.

Multiple studies have used different cutoff values for morphometric parameters of cam-type FAI..$^{92,94}$ Accordingly, more recent studies pointed out the high prevalence of radiographic findings that are suggestive of FAI in asymptomatic populations when applying currently used diagnostic thresholds, emphasizing the need for a reevaluation of these cutoffs. $^{84,94}$

Recognizing that a cam morphology was statistically prevalent at the anterosuperior FHN, an $\alpha$ angle value $>60$ degrees in the radial 1:30 plane was suggested as an upper threshold and predictor of hip pain. ${ }^{92}$ Individuals with a higher $\alpha$ angle, thus with a more severe deformity, had prevalent anterosuperior labral and cartilage lesions that were confirmed with open surgical hip dislocation and imaging. ${ }^{95,96}$

Presently it is acknowledged that Reflnt limits are beyond the abnormal thresholds initially reported in the literature. 


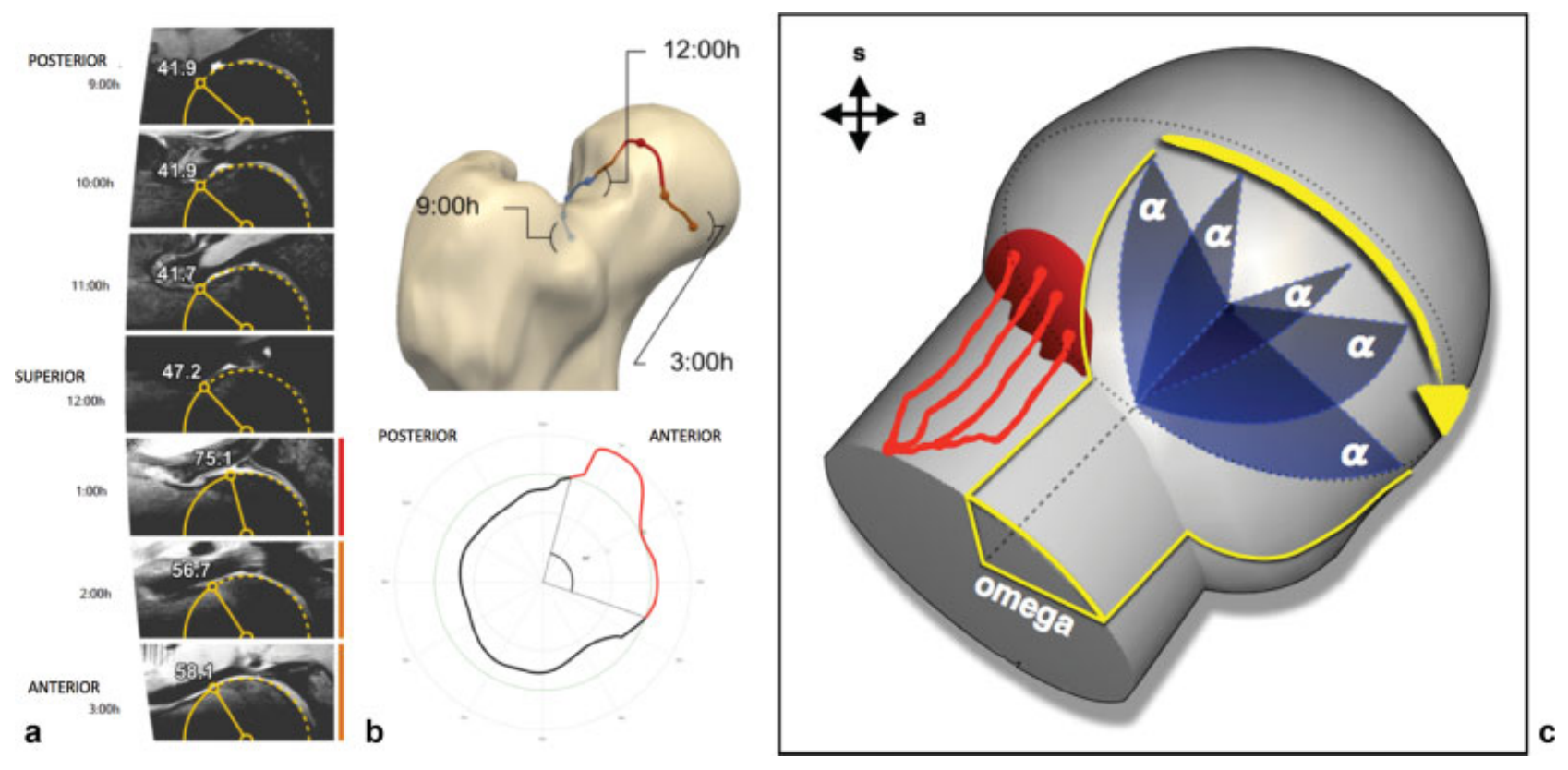

Fig. 13 (a) Volumetric three-dimensional (3D) magnetic resonance imaging $\alpha$ angle measurements made at different points around the femoral head/neck junction. The $\alpha$ angle is measured at 9 o'clock (posterior); 10, 11, and 12 o'clock (superior); and 1, 2, and 3 o'clock (anterior). (b) Upper image: 3D model representing the radial extension of the cam deformity (orange and red line representing increased $\alpha$ angles). Lower image: Polar plot (two-dimensional) of the 360-degree $\alpha$ angle around the femoral head-neck, representing the $\Omega$ angle (gray straight lines) and corresponding perimeter (red line) for a given $\alpha$ angle threshold ( 55 degrees). Red lines represent increased $\alpha$ angles for a given threshold. The $\Omega$ angle is formed by two lines intersecting the center of the femoral neck at the level of the head-neck junction. The most posterior line posteriorly intersects the point at which the $\alpha$ angle angle begins to be abnormal beyond a best fitting circle and the anterior line at the point where the $\alpha$ angle returns to normal. (c) Schematic drawing of the proximal femoral head. Retinacular vessels at the posterosuperior quadrant are represented (red lines and dots), with corresponding relationship with the radial angular measurement of the cam deformity ( $\Omega$ angle; yellow lines) defined by increased $\alpha$ angle at the anterosuperior quadrant (blue lines).

Revisiting the current $\alpha$ angle intervals used in the diagnosis of cam and FAIS is paramount. Conceptually, increasing the threshold of an abnormal $\alpha$ angle would improve its specificity, prevent overdiagnosis of FAIS, and consequently decrease the number of unnecessary surgeries..$^{93,97}$

Reference intervals: Based on several large asymptomatic cohorts (-Table 4), an $\alpha$ angle upper-limit RefInt of 60 degrees for the 12:00/3:00 positions and 65 to 70 degrees for the 1:00/1:30 o'clock positions was proposed. ${ }^{27,51}$ Although higher than the previously published thresholds of 50 to 55 degrees, ${ }^{86,92}$ these results are in agreement with several recent works, namely, from Agricola et $\mathrm{al}^{97}$ (who also measured the $\alpha$ angle at the 12:00 position), which is similar to a recent report using $\mathrm{MRI}^{93}$ (that suggested increasing the threshold to 63/66 degrees at 3:00/1:30 o'clock, respectively) and a population-based report ${ }^{52}$ (mean $\alpha$ angle of $59 \pm 9.4$ degrees).

Reference intervals with clinical impact ("decision limits"): Increasing the threshold of an abnormal $\alpha$ angle, while considering its discriminative ability, will additionally improve its value as a diagnostic test (i.e., introducing a useful "decision limit"). Therefore, we suggest using the threshold of an abnormal $\alpha$ angle in the setting of a diagnostic test to incorporate higher discriminative power. An upper $\alpha$ angle limit of 57 to 60 degrees measured at 1:00/ 1:30/2:00 o'clock and 50 degrees at 3:00 o'clock would optimize discriminative power while favoring specificity for a FAIS diagnosis. ${ }^{53}$

\section{Key Points}

1. The $95 \%$ reference interval limits of cam morphotype are beyond, that is, higher, than currently defined thresholds.

2. Epidemiological reference intervals: $95 \%$ reference interval $\alpha$ angle upper limit of 60 degrees for the 12:00/3:00 o'clock positions and 65 to 70 degrees for the 1:00/1:30 o'clock positions.

3. Decision limit: An upper $\alpha$ angle limit of 57 to 60 degrees measured at 1:00/1:30/2:00 o'clock and 50 degrees at 3:00 o'clock optimizes discriminative power while favoring specificity for a diagnosis of FAIS.

\section{Offset and Offset Ratio}

Another way to assess the FHN junction is to measure the offset. Anterior offset is the difference between the anterior femoral neck radius and the anterior femoral head radius, initially described in a cross-table radiographic view although later used in both CT and MRI. ${ }^{84}$ The anterior head-neck offset ratio is defined as the offset divided by the diameter of the femoral head ${ }^{98}$ (-Fig. 14).

The offset has been proved to differ in patients versus controls, showing a significant reduction in mean head-neck 


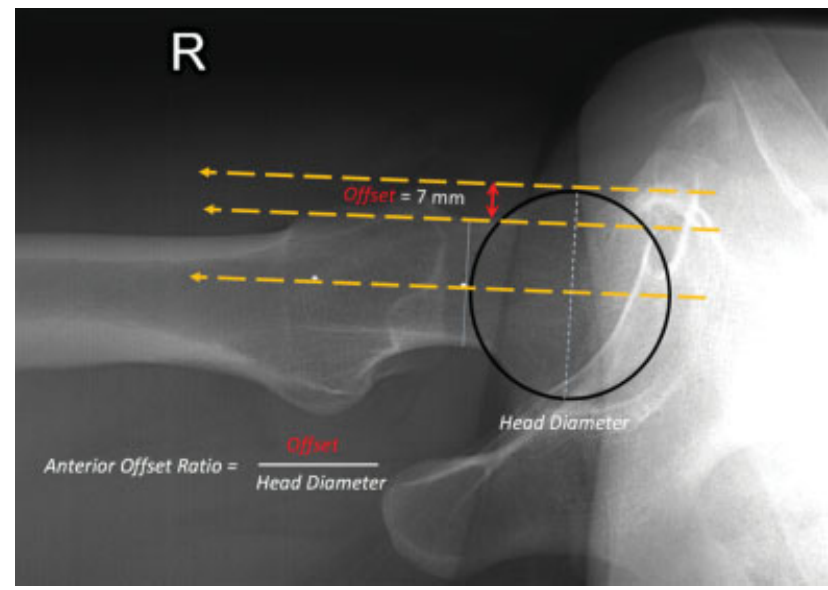

Fig. 14 Right hip cross-table lateral view. To calculate the offset, three parallel lines are drawn, the first line passing through the center of the long axis of the femoral neck, the second line through the anterior aspect of the femoral neck, and the third line through the anterior aspect of the femoral head. The head-neck offset is calculated by measuring the distance between the second and third lines.

offset on the anterior aspect of the femoral neck in the symptomatic group, consistent with the site of impingement in flexion and internal rotation, and with lesions of the adjacent rim. ${ }^{99}$

In asymptomatic hips, an anterior offset of $11.6 \pm 0.7 \mathrm{~mm}$ was considered normal; hips with cam impingement had a decreased anterior offset of $7.2 \pm 0.7 \mathrm{~mm}$ in the initial study conducted by Eijer et al. As a general rule for clinical practice, an anterior offset $<8 \mathrm{~mm}$ is an indicator for risk of cam impingement. ${ }^{8,84,100}$ Smaller offset values indicate the presence of a cam-type deformity. An offset ratio $\leq 0.15$ was proposed as representing a risk for impingement, ${ }^{101}$ and $\leq 0.17$ was considered pathologic ${ }^{102}$ (online - Supplementary Table 2 ).

Interobserver agreement (intraclass correlation coefficient [ICC]) was reported to be good (0.657) for offset, however, with ROC analysis and AUC $<0.666 .{ }^{103}$ The interclass and intraclass agreement for anterior offset was reported to be good $(>0.72) .{ }^{102}$

\section{Anterior Femoral Distance and Femoral Distance}

In an attempt to find a more reliable tool for discrimination between symptomatic patients and healthy individuals, anterior femoral distance (AFD), femoral distance (FD), and offset were suggested as alternative methods to the $\alpha$ angle for measuring cam-type deformities (-Fig. 15).

Anterior femoral distance: The AFD method was introduced by Lohan et al, ${ }^{88}$ as an alternative MRI measurement of femoral neck overgrowth (performed in a MR arthrographic study using the axial oblique sequence along the center of the femoral neck when cross-referenced to coronal images through the hip, ensuring that the fovea capitis was visible). ${ }^{88,103}$ AFD corresponds to the perpendicular distance between a line drawn along the cortex of the anterior aspect of the anterior femoral neck and the point of maximal FHN overgrowth. ${ }^{103}$

Femoral distance: Ehrmann et al $^{103}$ developed and adapted AFD measurement, where FD was measured between a line through the cortex of the femoral neck parallel to the central axis of the neck and the point of greatest femoral head-neck

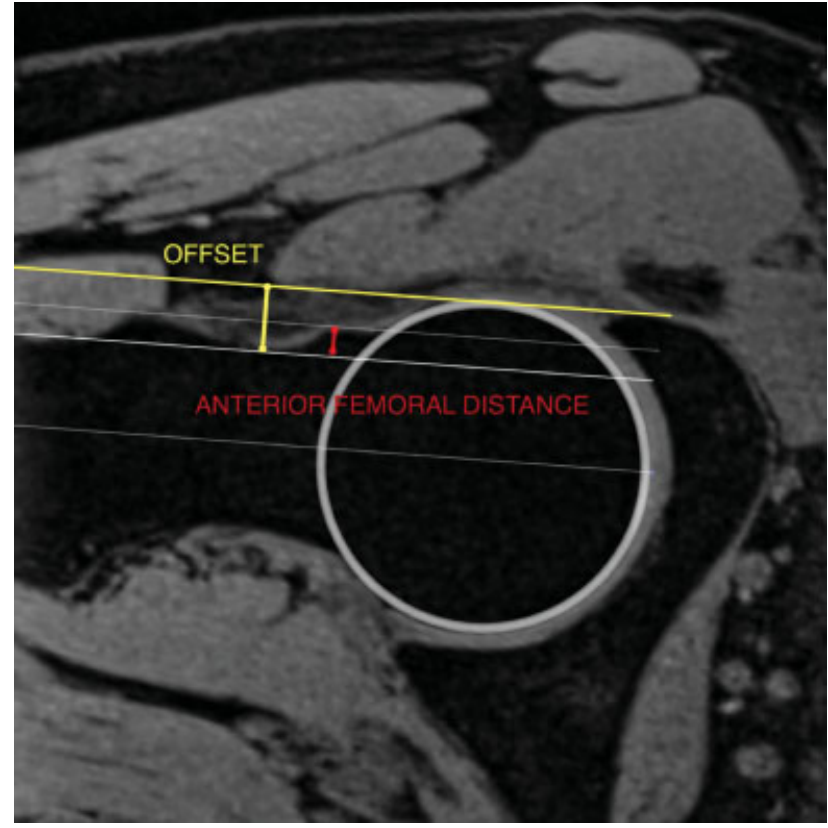

Fig. 15 Right hip magnetic resonance imaging three-dimensional axial oblique reformat trough the long femoral neck axis (3 o'clock). OFFSET (yellow line): the measurement of the offset (in millimeters) was originally described at the anterior position. A line is drawn along the central axis of the femoral neck (that does not necessarily run through the center of the femoral head). Parallel lines are then drawn along the cortex of the femoral neck and along the most peripheral part of the femoral head. The offset is defined as the perpendicular distance between the line at the femoral neck cortex and the outer femoral head. FEMORAL DISTANCE (red line): The greatest perpendicular height of epiphyseal deformation at the femoral head-neck junction was originally measured and described at the anterior position by Lohan et al (anterior femoral distance). The perpendicular distance between a tangent along the cortex of the anterior femoral neck and the point of greatest femoral head-neck overgrowth was measured in the anterior position.

overgrowth (around the FHN). Larger FD values indicate the presence of a cam-type deformity. They confirmed that the best position for AFD measurement/discrimination in camtype FAI is the anterosuperior segment.

Lohan et al considered AFD values $>3.6 \mathrm{~mm}$ to be abnormal. Ehrmann et al $^{103}$ suggested a lower FD threshold in the anterior and anterosuperior position $>2.2 \mathrm{~mm}$. Using a higher threshold than $2.2 \mathrm{~mm}$ resulted in a higher sensitivity but distinctly decreased specificity for discriminating asymptomatic individuals and patients with cam-type deformities (online - Supplementary Table 2). Overall, ICC was reported as good (offset: $0.657 /$ FD 0.632). ${ }^{103}$

However, neither offset nor FD measurements individually offer an advantage over the $\alpha$ angle for assessing the FHN junction in patients with suspected FAI. ${ }^{88,103}$

\section{Femoral Neck-Shaft Angle}

\section{General Considerations}

The femoral neck-shaft angle (NSA), or caput-collum-diaphyseal angle, is an anatomical measure for the geometric assessment of the proximal femur. The biomechanical and 
clinical significance of the NSA is underlined by its involvement in the decision-making process for hip-preserving surgery. It is routinely assessed in pediatric orthopaedics during the management of DDH and Perthes disease as well as in the planning of fracture treatment and osteotomies. ${ }^{104}$ A hip with a varus femoral neck ( $<120$ degrees) was reported as being subjected to higher mechanical stress, ${ }^{105}$ greater risk of labral tears, and prone to developing early symptoms. $^{106}$

Methodology of NSA measurement, defined as the angle between the FNA and femoral long axis, varies significantly in the literature ${ }^{107}$ because hip rotation along with femoral torsion influence the projected NSA on radiographs (at least four different methods were described for pelvis radiographs) $)^{107}$ (-Fig. 16).

Due to rotational influences and imprecise positioning of the femoral shaft and neck axis, reliability of the NSA measured on AP XR was challenged. ${ }^{107,108}$ Although AP XR is susceptible to rotational errors, CT or MRI-based coronal reconstruction of the proximal femur along the femoral neck plane can conceptually allow the correct measurement of the NSA. In a XR-based systematic review, the intraobserver and the interobserver correlation coefficients ranged between 0.76 and 0.95 and 0.58 and 0.89 , respectively. ${ }^{107}$

The difference between the rotation-corrected NSA and noncorrected measurements was reported to be 1 degree in a XR systematic review ${ }^{107}$ and 2.87 degrees in a CT-based study. ${ }^{108}$ Boese et al found significantly higher NSA values in the simulated pelvic AP XR (noncorrected in the APP) when compared with the exact coronal reconstructions (however no more than $\sim 3$ degrees). ${ }^{108}$

Age and sex influence the NSA although to a small extent (no more than 2-4 degrees between age extremes and the sexes). Varus hips increase with age in both sexes. Higher mean NSA values are seen in females compared with males. ${ }^{53,108}$

\section{Thresholds}

There is a high variability of reported NSA RefInt, mainly due to the variability of measurement methods used and to a lesser extent on account of rotation-correction variations. ${ }^{107,108}$

Mean NSA values between 129 and 132 degrees were observed in some recent XR- and CT-based reviews in large cohorts. As such, a 95\% RefInt between 120 degrees and 140 degrees can be considered the expected epidemiological RefInt (online - Supplementary Table 3).

Interestingly, in the presence of a cam morphology, a decreased NSA was acknowledged as a useful parameter to identify hips at risk of symptomatic FAI. ${ }^{74}$

\section{Triangular Index}

Gosvig et al $^{109}$ demonstrated that cam morphology of the FHN may be detectable on standardized AP pelvic and/or lateral radiographs when applying the triangular index $(\mathrm{TI})^{98,109}$ (-Fig. 17). This method provides an additional description of the cam morphology in both radiographic projections, ${ }^{98}$ although it is difficult to use in clinical practice.

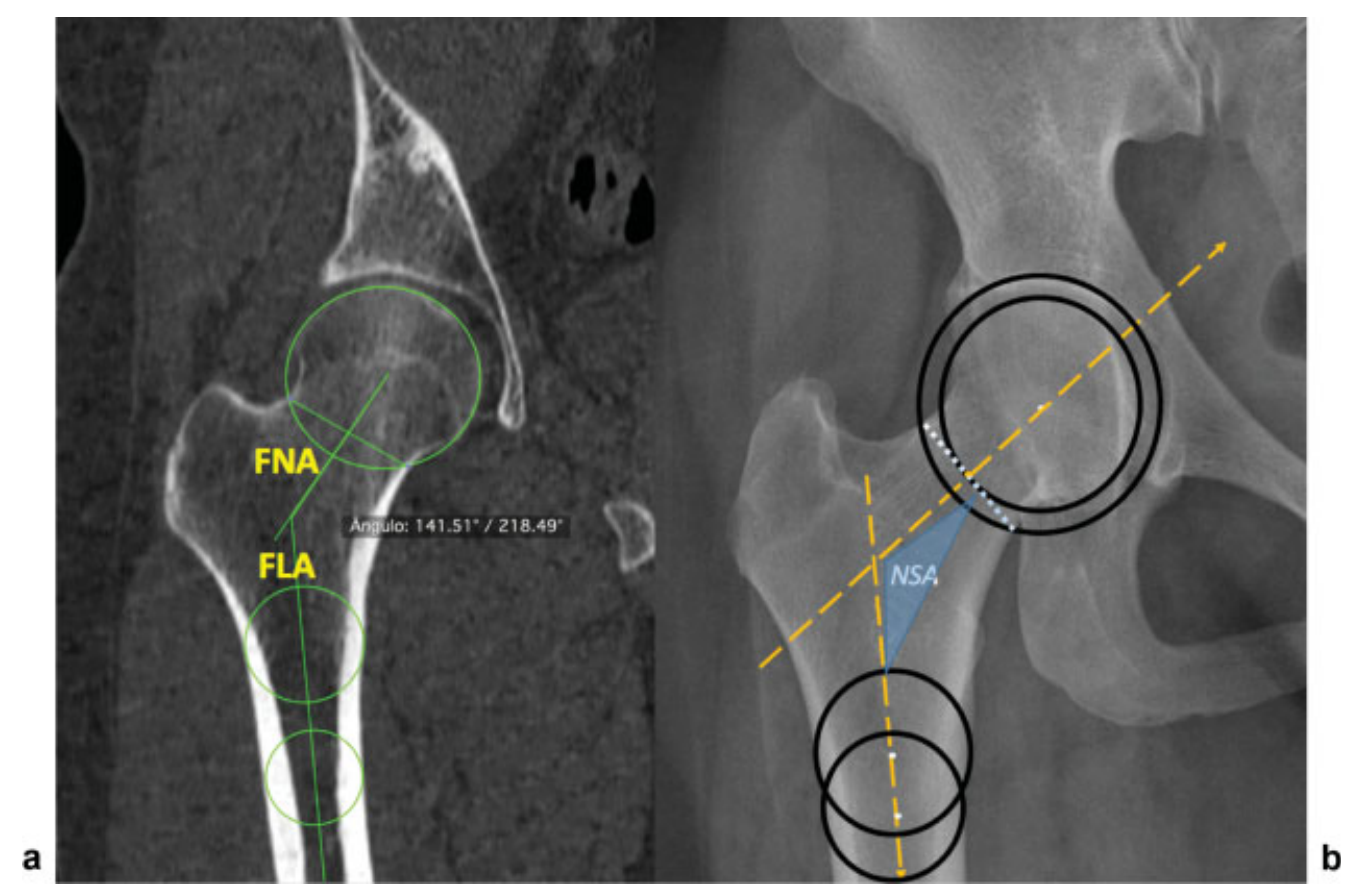

Fig. 16 Neck-shaft (NSA) angle measurements. (a) Right hip computed tomography reformat. (b) Right hip anteroposterior pelvic radiograph. Femoral neck axis (FNA) and femoral long axis (FLA). FNA is usually defined by a line connecting the femoral head center (FHC) and the femoral neck center (FNC). The FHC is usually the center of a circle defined by three points around the circumference of the femoral head (that can be challenging in hips with head deformity). The FNC can be defined reproducibly by the proposed method of Müller as the center between the cutting points of a circle centered on the FHC and the lower and upper margin of the waist segment of the femoral neck. To define the FLA, the best reproducibility can be expected by using the method of Clark et al, represented by a line crossing the center of two circles placed in the femur at two positions. The center of the first circle is positioned at the level of the lesser trochanter and the second circle $2 \mathrm{~cm}$ below the first. The circles should coincide with the outer margins of the femur. 


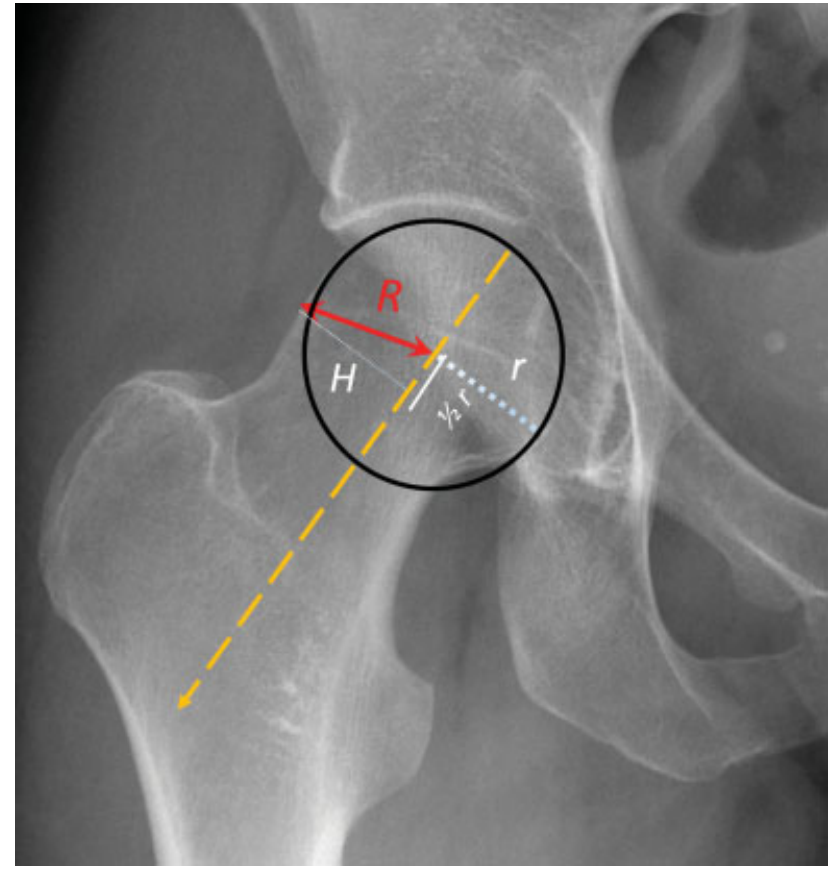

Fig. 17 Anteroposterior radiographic view of the right hip on a 28year-old woman. Diagram showing the triangular index for assessment of the asphericity of the femoral head and cam morphology. The radius $(r)$ of the femoral head is measured. Then $1 / 2 r$ and the corresponding perpendicular height $(\mathrm{H})$ to the cortex are measured. The radius $(R)$ is found by applying the Pythagorean law for triangular figures $\left(a^{2}+b^{2}=c^{2}\right)$. If $R \geq r+2 m$ on a radiograph, with 1.2 magnification, asphericity is demonstrated.

TI is positive if the pathologically increased radius $(R)$ is greater than the normal radius $(r)$ plus $2 \mathrm{~mm}((\mathrm{R}) \geq(\mathrm{r})+2$ $\mathrm{mm})$. No significant correlation in terms of age, sex, and the TI could be detected. ${ }^{109}$

\section{Omega Angle}

\section{General Considerations}

$\mathrm{XR}, \mathrm{CT}$, and MRI techniques for measuring cam-type FAIS have until now provided only a 2D characterization of FHN morphology because measurements are made on a limited series of slices, ${ }^{15}$ and $\alpha$ angle measurement is performed in only one plane. As such, it is highly dependent on the position at which it is measured. ${ }^{27}$ Hence MRI and CT 3D reconstructions allow for adequate corrections of femoral head centering and provide a more accurate depiction of femoral morphology. ${ }^{27}$ The $\Omega$ angle was introduced by Rego ${ }^{110}$ on 2D MRI and by Mascarenhas et $\mathrm{al}^{27,51,53}$ on 3D CT and 3D MRI. It is a 3D angular measurement that allows the location and extent of cam morphologies to be quantified (stepping up to a 3D perception of the cam morphology by determining its radial extension). This angle quantifies the extent of abnormally elevated $\alpha$ angles, providing information on cam magnitude (defined by the radial extension of the FHN deformity). Significant positive correlations are seen between the $\Omega$ and $\alpha$ angles (increasing values of the $\alpha$ angle correlate to higher values of the $\Omega$ angle). ${ }^{27}$
The $\Omega$ angle can be more easily obtained from 3D images, calculating the clockwise 360-degree $\alpha$ angle. The $\Omega$ angle is formed by measuring the angle corresponding to the three points formed by the center of the femoral head, the point where the $\alpha$ angle begins to be abnormal beyond a best fitting circle, and the final one where the $\alpha$ angle returns to a normal value ${ }^{27}$ (-Fig. 13).

This novel quantitative measure was shown to have diagnostic $^{27,53}$ and treatment-planning ${ }^{110}$ capabilities. The importance of this parameter was additionally outlined by an arterial topographic study of the proximal femur. ${ }^{111}$

\section{Thresholds}

Mascarenhas et al found that symptomatic patients have larger cam deformities (defined by increased $\Omega$ angles and $\alpha$ angles) than asymptomatic volunteers. Mean $\Omega$ angle differences of $27 \pm 24$ degrees (asymptomatic) versus $66 \pm 32$ degrees (symptomatic patients) were depicted, with an optimal $\Omega$ angle threshold of 43 degrees (sensitivity 72\%, specificity 70\%; AUC: 0.830 ) observed as one of the best parameters to discriminate asymptomatic from symptomatic hip patients. ${ }^{53}$

\section{Key Points}

1. Although other 2D parameters exist to appreciate FHN morphology, to date none has demonstrated superiority to the $\alpha$ angle.

2. The $\Omega$ angle has a supplementary role to the $\alpha$ angle because it measures the radial span of a cam morphology.

\section{Femoral Torsion}

\section{General Considerations}

Femoral torsion represents the amount of rotation or torsion between the proximal and distal parts of the femur. It is the angle between two planes: the plane through the long diaphyseal axis of the femur (LFA) (parallel to the line connecting the dorsal aspect of the medial and lateral femoral condyles) and the plane containing the FNA. ${ }^{112}$ This angle is usually positive; that is, the femoral neck is normally anteverted in relation to the axis of the femoral condyles.

Abnormalities of femoral torsion have been investigated for decades and associated with several hip disorders, such as hip dysplasia, slipped capital femoral epiphysis, or OA. ${ }^{113,114}$ More recently, they were the focus of renewed attention due to their relation with several types of hip impingement, ${ }^{115,116}$ particularly the combination of cam-type FAIS with reduced torsion, ${ }^{117}$ because decreased femoral torsion may exacerbate ${ }^{118}$ or even outweigh ${ }^{119}$ the effect of a cam morphology and further impair hip internal rotation, aggravating early femoroacetabular contact. 
In a study carried out by Lerch et al, ${ }^{120}$ every 1 in 6 patients with hip pain attributed to FAI or DDH presented with an abnormal femoral torsion. They also found abnormal values of torsion in $74 \%$ of symptomatic hips where no obvious pathomorphology could be detected on radiographs. In fact, rotational deformities, along with camand pincer-type morphologies, are now considered one of the three major osseous contributors to FAI. Accordingly, because abnormalities of femoral torsion may cause damage to the hip ${ }^{121}$ and affect outcomes of hip-preserving surgery, excessive anteversion or retroversion may need to be addressed surgically by derotational osteotomies. Thus assessment of torsion in young patients with hip pain is mandatory. $^{119}$

Interestingly, patients with pincer-type FAIS have a larger femoral antetorsion than patients with cam-type FAIS, ${ }^{115}$ although this parameter per se does not differ significantly between symptomatic and healthy individuals. ${ }^{53,115}$ Recently, the supra- and infra-trochanteric components of femoral torsion were demonstrated to differ substantially between hip disorders because patients with DDH have predominantly increased infra-trochanteric torsion, whereas patients with pincer-type FAIS have increased supra-trochanteric torsion. ${ }^{122}$

Femoral torsion decreases significantly from birth until skeletal maturity, ${ }^{123}$ remaining stable afterward. An association with side and sex was also reported, with lower antetorsion values on the right hip and in males compared with females. ${ }^{115,121}$

Initially, femoral torsion was measured on radiographs, ${ }^{31}$ but CT and MRI are currently the preferred modalities to determine this parameter. ${ }^{124}$ Although a globally accepted measurement method remains to be ascertained, adequate anatomical measurements of femoral torsion can be performed on CT and MRI systematically using strict axial slices. ${ }^{115,125}$ Biplanar radiographs with $3 \mathrm{D}$ modeling are being increasingly used for torsional assessment and constitute a low-dose alternative to CT with comparable results. ${ }^{124}$ The 3D-based measurements were reported to be reproducible and independent of femur positioning, overcoming major reproducibility issues encountered with 2D methods. ${ }^{126}$

Various measurement methods are reported in the literature for assessing this angle. ${ }^{127}$ Although defining the axis of the femoral condyles is consensual, the definition of the FNA has been extensively debated, and at least five methods can be used (-Fig. 18).

One method (Jarret et al) uses oblique axial slices of the proximal femur, parallel to the femoral neck, instead of the standard strict transverse plane. ${ }^{117,125}$ This method allows drawing the FNA more quickly because the whole femoral neck can be visualized on a single slice, but it yields slightly lower values of femoral antetorsion. ${ }^{125}$ A trigonometric conversion formula was described, and an online converter is available (femoral antetorsion converter, available at http://www.antetorsion.org. Accessed November 20, 2018), which may accurately predict the standard measurements using the oblique axial values.
The other four methods define the FNA either by using a single axial slice through the neck (Lee et al) ${ }^{128}$ or two axial slices, in which one passes through the femoral head and the other through the center of the greater trochanter (Tomczak), ${ }^{129}$ at the level of the lesser trochanter center (Murphy et $\mathrm{al})^{112}$ or at the center of the femoral neck (Reikeras). Interestingly, the more caudal this angle is measured, the higher the values of torsion are obtained.

\section{Thresholds}

Normal values of femoral torsion angles reported in the literature vary significantly. ${ }^{125,127}$ This is largely related to the method of measurement used (as previously stated, specifically to differences in how the center of the neck and proximal femoral axis are defined ${ }^{112}$ ). Inter- and intraobserver variability may also account for the wide range of normal values reported in the literature. ${ }^{127}$ In addition, 2D measurements of 3D structures are prone to bias. Although not used routinely in clinical practice, automated analysis software may in the future help overcome some of these issues. $^{130}$

The choice of imaging technique also matters. Although high correlation was found between CT- and MRI-based measurements, there is a trend toward slightly higher absolute values on $\mathrm{CT}$. $^{117}$

Therefore, reference intervals of femoral torsion depend on the imaging modality and method of measurement used, and it may be necessary to apply different thresholds accordingly. $^{117}$

Tönnis and Heinecke et al estimated that 15 to 20 degrees is the normal range for femoral antetorsion based on XR and CT data, ${ }^{63}$ and Sutter et al $^{115}$ reported mean values of $12.8 \pm 10.1$ degrees in asymptomatic adults using MRI. Other authors obtained similar results in symptomatic and asymptomatic adults using the Reikeras et al technique (online - Supplementary Table 4).

\section{Spinopelvic Parameters}

\section{General Considerations}

Sagittal (spinopelvic) balance of the spinal column is an evolutionary adaptation that became necessary for humans to adopt a vertical posture. The spine and pelvis have a synergistic relationship, and studies showed that a link exists between these structures and the development of spine pathology. ${ }^{131}$

In 1992, Duval-Beaupère et $\mathrm{al}^{132}$ first established an anatomical parameter they named the "angle of sacral incidence" that later became known as "pelvic incidence" (PI). This parameter is defined as the angle between the line perpendicular to the sacral plate at its midpoint and a line from the midpoint between the axis of the two femoral heads to the center of the upper surface of the sacrum.

Besides PI, two other morphometric spinopelvic parameters have been described that are interrelated, namely, sacral slope (SS) and pelvic tilt (PT) ${ }^{133}$ (- Table 5).

PT and SS are dynamic parameters that change with hip motion and position. PI, in contrast, is a fixed parameter for 


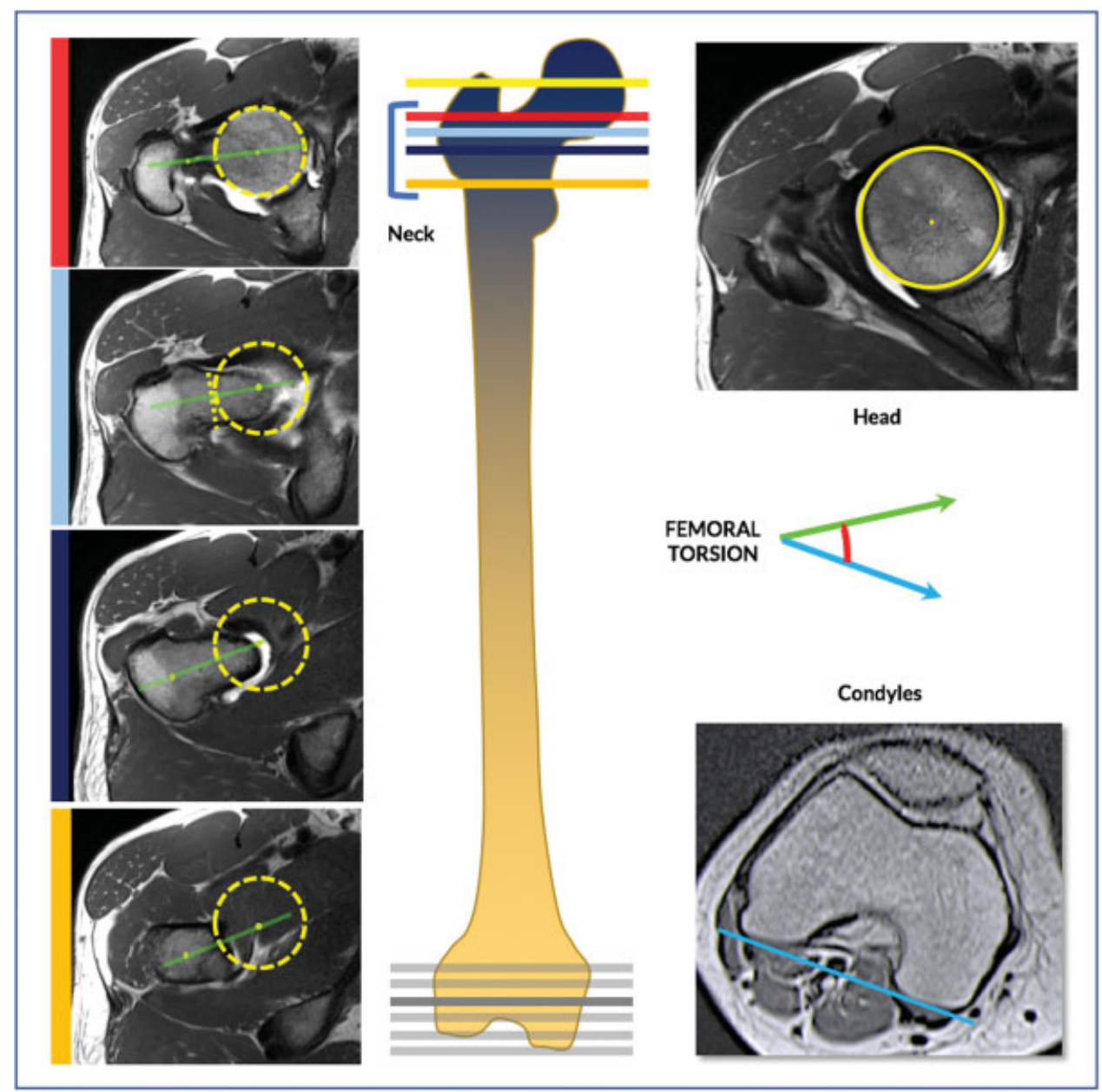

Fig. 18 Assessment of femoral torsion on cross-sectional imaging. On consecutive strict axial images over the proximal femur, determine the femoral head center (FHC) (yellow circle and yellow line). Defining the femoral neck axis (green line) can be obtained by several methods. Lee (red bar): A line is drawn on the first image on which the FHC can be connected with the most cephalic junction of the greater trochanter and the femoral neck; Reikeras (light blue bar): A line connecting the FHC with the femoral neck center is drawn on an image where the anterior and posterior cortices run parallel to each other; Jarret (not shown): A line is drawn on a single image that runs from the FHC trough the center of the femoral neck. Tomczak (dark blue bar): The FHC is connected with the center of the greater trochanter at the base of the femoral neck. Murphy (orange bar): The FHC is connected with the center of the base of the femoral neck directly superior to the lesser trochanter. Then, over the distal femur, draw a tangent to the posterior aspect of the femoral condyles (blue line; choosing the slice where the condyles are more prominent). The angle between both lines represents the femoral torsion. Although some of these reference points are located on different adjacent slices, modern workstations should allow drawing and modifying a line across multiple images in one series or, alternatively, different slices can be superimposed on a single image with the help of postprocessing software.

each individual. In brief, PT and SS depend on posture (higher SS when supine and lower when standing) and conjointly compose PI, which is an individual position-independent angle. This dynamic "unit" may change in response to postural changes to maintain vertebral and pelvic sagittal balance ${ }^{134}$ (-Fig. 19).

Spinopelvic parameters (SPPs) can be measured using lateral lumbosacral radiographs, ${ }^{135,136}$ pelvic CT images, ${ }^{137}$ and pelvic MRI. ${ }^{53,138}$ Very few studies have addressed differences between measurements on distinct imaging modalities; Moon et $\mathrm{al}^{139}$ found an increase in SS and a decrease in PT and PI (SS increased by 3.5 degrees, PT decreased by 6.7 degrees, and PI decreased by 3.2 degrees) when comparing XR and CT measurements, which might be associated with positional and methodological changes. Variability in standing to sitting position was described for PT, ${ }^{140}$ and difference in measurements pertaining to XR (standing) and CT (decubitus) modalities were studied for all spinopelvic parameters. ${ }^{139}$ MRI and CT 3D reconstructions allow for adequate corrections of femoral head centering and could provide a more accurate depiction of pelvic morphology. ${ }^{53}$

With regard to pathology, there is a direct relationship between lumbar lordosis and SS, and a strong positive correlation between PI and sacral kyphosis was identified. ${ }^{141}$ Han et al concluded that a high PI value in patients with degenerative lumbar scoliosis might be associated with the high prevalence of degenerative lumbar spondylolisthesis. Also, in patients with isthmic spondylolisthesis, greater SPP values are associated with a greater slip grade. $^{142}$ 
Table 5 Spinopelvic parameters: definition of pelvic incidence, sacral slope, and pelvic tilt

\begin{tabular}{|l|l|l|l|}
\hline Parameter & Values & Radiograph & Definition \\
\hline PI & (angle) & $\begin{array}{l}\text { Standing sagittal } \\
\text { lumbosacral }\end{array}$ & $\begin{array}{l}\text { Angle between the line perpendicular to the sacral plate at its } \\
\text { midpoint and a line from the midpoint between the axis of the } \\
\text { two femoral heads to the center of the surface of the sacrum } \\
\mathrm{PI}=\text { SS + PT }\end{array}$ \\
\hline SS & (angle) & $\begin{array}{l}\text { Standing sagittal } \\
\text { lumbosacral }\end{array}$ & $\begin{array}{l}\text { Angle formed by a line drawn parallel to the end plate of the } \\
\text { sacrum to a horizontal reference line }\end{array}$ \\
\hline PT & (angle) & $\begin{array}{l}\text { Standing sagittal } \\
\text { lumbosacral }\end{array}$ & $\begin{array}{l}\text { Angle formed by a line from the midpoint of the sacral end plate } \\
\text { to the center of the femoral heads and a vertical plumb line }\end{array}$ \\
\hline
\end{tabular}

Abbreviations: PI, pelvic incidence; PT, pelvic tilt; SS, sacral slope.

Demographic factors were reported to influence SPP, namely, sex and age, however with contradictory results. Higher PT and PI were reported, although not universally, in female subjects. ${ }^{139}$ Interestingly, Mascarenhas et $\mathrm{al}^{53}$ found higher SS and PI in asymptomatic females compared with asymptomatic males, whereas opposite observations were depicted when only considering symptomatic subjects. Some authors ${ }^{143}$ concluded that pelvic parameters are not statistically different between sexes.

With respect to age, PI and PT were found to increase with age. ${ }^{134,139}$ Similarly, Mac-Thiong et al described a weak correlation of spinopelvic parameters with age. ${ }^{144}$ Some

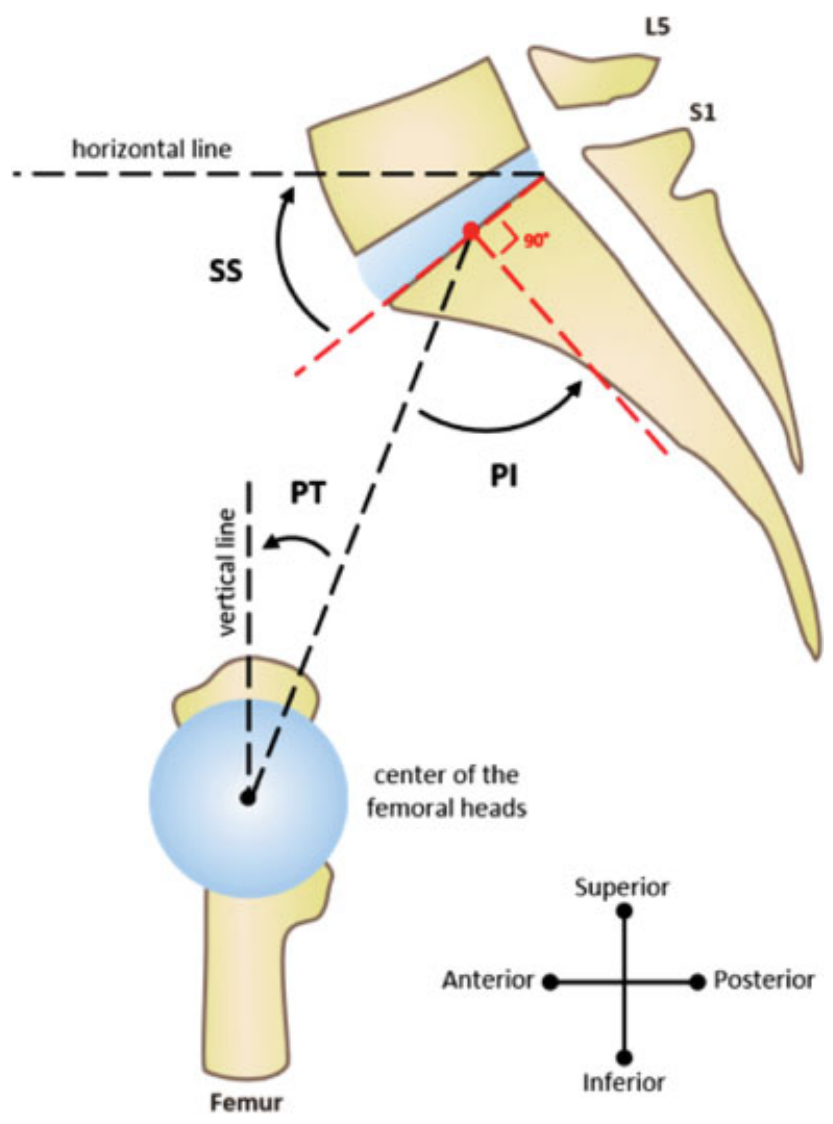

Fig. 19 Imaging spinopelvic parameters. - Table 5 lists the definitions. PI, pelvic Incidence; PT, pelvic tilt; SS, sacral slope. studies showed no statistically significant difference. ${ }^{139,145}$ Others also found an increased PT and decreased SS with aging. ${ }^{146,147}$

Evaluation among different ethnic groups showed that mean PI is similar in Japanese and lower in Mexicans and Asians as compared with whites. ${ }^{148}$ Zhu et al found that subjects from Chinese population had a significantly smaller PI and SS than those from white populations. ${ }^{134}$

Another study performed between groups with different body mass indices showed that spinopelvic parameters are practically equal among different weight populations. ${ }^{149}$

\section{Thresholds}

Currently no normative values are established for PI, SS, and PT because there is a high variability of measured values among asymptomatic individuals (online - Supplementary Table 5). Roussouly et al ${ }^{150}$ studied 160 individuals and established the following means: $51.9 \pm 10.7$ degrees for PI, $39.9 \pm 8.1$ degrees for SS, and $11.9 \pm 6.4$ degrees for PT, respectively. A study performed among 709 asymptomatic adults without spinal pathology established similar values for PI (52.6 \pm 10.4 degrees), SS (39.6 \pm 6.8 degrees) and PT $(13.0 \pm 6.8$ degrees $){ }^{143}$

Relationship of sagittal balance and hip disorders is currently controversial. ${ }^{151} \mathrm{PI}$ is an indicator of acetabular retroversion, ${ }^{152}$ and patients with a higher PI have more anteriorly positioned femoral heads and a better ability to compensate for sagittal imbalance with pelvic retroversion. ${ }^{150}$ Sagittal rotation also changes the socket orientation of the acetabulum, contributing to or protecting from FAI: The L-CEA and percentage of acetabular crossover increases with pelvic forward tilt and decreases with back tilt. ${ }^{153}$

FAIS patients were recently shown to have higher PI and SS angles. ${ }^{53,74}$ Recently, Mascarenhas et $\mathrm{al}^{53}$ showed that increased SPPs are predictive of a hip symptomatic state, and $\mathrm{Ng}$ et $\mathrm{al}^{137}$ corroborated this finding for PI. A significant contribution of these parameters for a symptomatic hip ${ }^{53,137}$ and $\mathrm{OA}^{135,136}$ was suggested. In fact, decreasing values of SS may allow greater impingement-free hip flexion by effectively reducing femoral coverage anteriorly. Saltychev et al, ${ }^{151}$ however, challenged this relationship as not showing evidence of a substantial role of pelvic incidence in hip 
disorders, suggesting a possible association of lower PI with FAI.

\section{Key Points}

1. Femoral torsion determination is mandatory in the young adult hip because it is one of the three major osseous factors that can lead to the development of FAIS. Its thresholds vary greatly with the measurement method used (consistency is recommended).

2. Spinopelvic parameters are increasingly recognized as a major contributor (fourth contributor along with cam, acetabulum morphology, and femoral torsion) to hip pathology.

\section{Conclusion and Future Directions}

The totality of the information presented in this synopsis, addressing imaging of the hip joint, shows that we have gained an enhanced ability to assess the problematic hip. From defining normal anatomy to identifying critical lesions, the current diagnostic modalities will continue to play an important role in the clinician's armamentarium. With a standardized approach and technique, the causes of hip dysfunction and disability can be identified successfully. Likewise, as our understanding of anatomical structures and pathologic findings in the symptomatic hip improve, the understanding of the indications for imaging modalities, definitions of normative values, and assessment of pertinent findings will also improve. It is not uncommon to identify "pathologic" findings in the asymptomatic population, ${ }^{5}$ and determining which imaging findings are associated with symptoms and require intervention will become an increased point of emphasis in the future. ${ }^{53}$

The future of imaging of the hip will build on the defined parameters of the modalities discussed here. For example, the ability to identify early cartilage lesions with the use of T2 cartilage mapping sequences and delayed gadoliniumenhanced MRI will aid the clinician to identify the at-risk hip. ${ }^{154}$ In these particular cases, enhanced surveillance with cost-effective imaging modalities will enhance patient care by facilitating early detection of injury and possibly treatment. Furthermore, the improved definition of the relationship between hip conditions and spinopelvic parameters will enable the clinician to optimize patient selection for specific treatments (surgical and nonsurgical). ${ }^{53}$ The promise of future improvements in imaging also leads one to ponder the prospects of correlating imaging findings with histologic findings or even with biomarkers of cartilage or soft tissue damage. ${ }^{155}$ This ability to correlate imaging with physiology is perhaps the next frontier. Likewise, correlating the outcomes of treatments such as surgery with postintervention imaging holds promise in helping the clinician assess the impact of intervention. If current challenges are met through focused investigation and directed innovation, it will be possible to continue enhancing patient care and clinical understanding of the hip joint.

Conflict of Interest

None declared.

\section{References}

1 Tijssen M, van Cingel R, Willemsen L, de Visser E. Diagnostics of femoroacetabular impingement and labral pathology of the hip: a systematic review of the accuracy and validity of physical tests. Arthroscopy 2012;28(06):860-871

2 Burnett RSJ, Della Rocca GJ, Prather H, Curry M, Maloney WJ, Clohisy JC. Clinical presentation of patients with tears of the acetabular labrum. J Bone Joint Surg Am 2006;88(07):1448-1457

3 Martin HD, Kelly BT, Leunig M, et al. The pattern and technique in the clinical evaluation of the adult hip: the common physical examination tests of hip specialists. Arthroscopy 2010;26(02): $161-172$

4 Griffin DR, Dickenson EJ, O'Donnell J, et al. The Warwick Agreement on femoroacetabular impingement syndrome (FAI syndrome): an international consensus statement. Br J Sports Med 2016;50(19):1169-1176

5 Mascarenhas VV, Rego P, Dantas P, et al. Imaging prevalence of femoroacetabular impingement in symptomatic patients, athletes, and asymptomatic individuals: a systematic review. Eur J Radiol 2016;85(01):73-95

6 Dickenson E, Wall PDH, Robinson B, et al. Prevalence of cam hip shape morphology: a systematic review. Osteoarthritis Cartilage 2016;24(06):949-961

7 Sutter R, Stoel BC, Buck FM, et al. Internal derangements of joints -past, present, and future. Invest Radiol 2015;50(09):601-614

8 Sutter R, Pfirrmann CWA. Update on femoroacetabular impingement: what is new, and how should we assess it? Semin Musculoskelet Radiol 2017;21(05):518-528

9 Clohisy JC, Carlisle JC, Beaulé PE, et al. A systematic approach to the plain radiographic evaluation of the young adult hip. J Bone Joint Surg Am 2008;90(Suppl 4):47-66

10 Mast NH, Impellizzeri F, Keller S, Leunig M. Reliability and agreement of measures used in radiographic evaluation of the adult hip. Clin Orthop Relat Res 2011;469(01):188-199

11 Ayeni OR, Chan K, Whelan DB, et al. Diagnosing femoroacetabular impingement from plain radiographs: do radiologists and orthopaedic surgeons differ? Orthop J Sports Med 2014;2(07): 2325967114541414

12 Nepple JJ, Martel JM, Kim YJ, Zaltz I, Clohisy JC; ANCHOR Study Group. Do plain radiographs correlate with CT for imaging of cam-type femoroacetabular impingement? Clin Orthop Relat Res 2012;470(12):3313-3320

13 Atkins PR, Shin Y, Agrawal P, et al. Which two-dimensional radiographic measurements of cam femoroacetabular impingement best describe the three-dimensional shape of the proximal femur? Clin Orthop Relat Res 2019;477(01):242-253

14 Smith KM, Gerrie BJ, McCulloch PC, Lintner DM, Harris JD. Comparison of MRI, CT, Dunn $45^{\circ}$ and Dunn $90^{\circ}$ alpha angle measurements in femoroacetabular impingement. Hip Int 2018; 28(04):450-455

15 Rakhra KS, Sheikh AM, Allen D, Beaulé PE. Comparison of MRI alpha angle measurement planes in femoroacetabular impingement. Clin Orthop Relat Res 2009;467(03):660-665

16 Bouma HW, Hogervorst T, Audenaert E, Krekel P, van Kampen PM. Can combining femoral and acetabular morphology parameters improve the characterization of femoroacetabular impingement? Clin Orthop Relat Res 2015;473(04):1396-1403

17 Laborie LB, Engesæter IØ, Lehmann TG, et al. Radiographic measurements of hip dysplasia at skeletal maturity-new 
reference intervals based on 2,038 19-year-old Norwegians. Skeletal Radiol 2013;42(07):925-935

18 Agricola R, Heijboer MP, Bierma-Zeinstra SMA, Verhaar JAN, Weinans H, Waarsing JH. Cam impingement causes osteoarthritis of the hip: a nationwide prospective cohort study (CHECK). Ann Rheum Dis 2013;72(06):918-923

19 Tannast M, Siebenrock KA, Anderson SE. Femoroacetabular impingement: radiographic diagnosis-what the radiologist should know. AJR Am J Roentgenol 2007;188(06):1540-1552

20 Tannast M, Fritsch S, Zheng G, Siebenrock KA, Steppacher SD. Which radiographic hip parameters do not have to be corrected for pelvic rotation and tilt? Clin Orthop Relat Res 2015;473(04): 1255-1266

21 Jackson TJ, Estess AA, Adamson GJ. Supine and standing AP pelvis radiographs in the evaluation of pincer femoroacetabular impingement. Clin Orthop Relat Res 2016;474(07):1692-1696

22 Wassilew GI, Heller MO, Janz V, Perka C, Müller M, Renner L. High prevalence of acetabular retroversion in asymptomatic adults: a 3D CT-based study. Bone Joint J 2017;99-B(12): 1584-1589

23 Zaltz I, Kelly BT, Hetsroni I, Bedi A. The crossover sign overestimates acetabular retroversion. Clin Orthop Relat Res 2013; 471(08):2463-2470

24 Ayeni OR, Karlsson J, Philippon MJ, Safran MR. Diagnosis and Management of Femoroacetabular Impingement. Cham, Switzerland: Springer International Publishing; 2016

25 Meyer DC, Beck M, Ellis T, Ganz R, Leunig M. Comparison of six radiographic projections to assess femoral head/neck asphericity. Clin Orthop Relat Res 2006;445:181-185

26 Lim S-J, Park Y-S. Plain radiography of the hip: a review of radiographic techniques and image features. Hip Pelvis 2015; 27(03):125-134

27 Mascarenhas VV, Rego P, Dantas P, Gaspar A, Soldado F, Consciência JG. Cam deformity and the omega angle, a novel quantitative measurement of femoral head-neck morphology: a 3D CT gender analysis in asymptomatic subjects. Eur Radiol 2017;27(05):2011-2023

28 Domayer SE, Ziebarth K, Chan J, Bixby S, Mamisch TC, Kim YJ. Femoroacetabular cam-type impingement: diagnostic sensitivity and specificity of radiographic views compared to radial MRI. Eur J Radiol 2011;80(03):805-810

29 Saito M, Tsukada S, Yoshida K, Okada Y, Tasaki A. Correlation of alpha angle between various radiographic projections and radial magnetic resonance imaging for cam deformity in femoral headneck junction. Knee Surg Sports Traumatol Arthrosc 2017;25 (01):77-83

30 Hipfl C, Titz M, Chiari C, et al. Detecting cam-type deformities on plain radiographs: what is the optimal lateral view? Arch Orthop Trauma Surg 2017;137(12):1699-1705

31 Dunn DM. Anteversion of the neck of the femur; a method of measurement. J Bone Joint Surg Br 1952;34-B(02):181-186

32 Lee $C B$, Spencer HT. Comparison of intraoperative fluoroscopic Dunn view with magnetic resonance imaging to determine femoral version. Arthroscopy 2017;33(06):1186-1193

33 Mascarenhas VV, Caetano A. Imaging the young adult hip in the future. Ann Joint 2018;3:47

34 Heyworth BE, Dolan MM, Nguyen JT, Chen NC, Kelly BT. Preoperative three-dimensional CT predicts intraoperative findings in hip arthroscopy. Clin Orthop Relat Res 2012;470(07): 1950-1957

35 Dandachli W, Najefi A, Iranpour F, Lenihan J, Hart A, Cobb J. Quantifying the contribution of pincer deformity to femoroacetabular impingement using 3D computerised tomography. Skeletal Radiol 2012;41(10):1295-1300

36 de Sa D, Horner NS, MacDonald A, et al. Evaluating healthcare resource utilization and outcomes for surgical hip dislocation and hip arthroscopy for femoroacetabular impingement. Knee Surg Sports Traumatol Arthrosc 2016;24(12):3943-3954
37 Mettler FA Jr, Huda W, Yoshizumi TT, Mahesh M. Effective doses in radiology and diagnostic nuclear medicine: a catalog. Radiology 2008;248(01):254-263

38 Hendee WR, O'Connor MK. Radiation risks of medical imaging: separating fact from fantasy. Radiology 2012;264(02):312-321

39 Samim M, Eftekhary N, Vigdorchik JM, et al. 3D-MRI versus 3D$\mathrm{CT}$ in the evaluation of osseous anatomy in femoroacetabular impingement using Dixon 3D FLASH sequence. Skeletal Radiol 2019;48(03):429-436

40 Yan K, Xi Y, Sasiponganan C, Zerr J, Wells JE, Chhabra A. Does 3DMR provide equivalent information as 3DCT for the preoperative evaluation of adult hip pain conditions of femoroacetabular impingement and hip dysplasia? Br J Radiol 2018;91 (1092):20180474

41 Lopes DS, Pires SM, Mascarenhas VV, Silva MT, Jorge JA. On a "Columbus' Egg": modeling the shape of asymptomatic, dysplastic and impinged hip joints. Med Eng Phys 2018;59(July):50-55

42 Stelzeneder D, Hingsammer A, Bixby SD, Kim Y-J. Can radiographic morphometric parameters for the hip be assessed on MRI? Clin Orthop Relat Res 2013;471(03):989-999

43 Fowkes LA, Petridou E, Zagorski C, Karuppiah A, Toms AP. Defining a reference range of acetabular inclination and center-edge angle of the hip in asymptomatic individuals. Skeletal Radiol 2011;40(11):1427-1434

44 Chadayammuri V, Garabekyan T, Jesse M-K, et al. Measurement of lateral acetabular coverage: a comparison between CT and plain radiography. J Hip Preserv Surg 2015;2(04):392-400

45 Harris-Hayes M, Commean PK, Patterson JD, Clohisy JC, Hillen TJ. Bony abnormalities of the hip joint: a new comprehensive, reliable and radiation-free measurement method using magnetic resonance imaging. J Hip Preserv Surg 2014;1(02):62-70

46 Air ME, Harrison JR, Nguyen JT, Kelly BT, Bogner EA, Moley PJ. Correlation of measurements of the prearthritic hip between plain radiography and computed tomography. PM R 2019;11 (02):158-166

47 Mantovani G, Ng KCG, Lamontagne M. Regression models to predict hip joint centers in pathological hip population. Gait Posture 2016;44:48-54

48 Tannast M, Hanke MS, Zheng G, Steppacher SD, Siebenrock KA. What are the radiographic reference values for acetabular underand overcoverage? Clin Orthop Relat Res 2015;473(04): 1234-1246

49 Boyd JC. Defining laboratory reference values and decision limits: populations, intervals, and interpretations. Asian J Androl 2010;12(01):83-90

50 Obuchowski NA, Subhas N, Polster J. Statistics for radiology research. Semin Musculoskelet Radiol 2017;21(01):23-31

51 Mascarenhas VV, Rego P, Dantas P, et al. Hip shape is symmetric, non-dependent on limb dominance and genderspecific: implications for femoroacetabular impingement. A 3D CT analysis in asymptomatic subjects. Eur Radiol 2018;28 (04):1609-1624

52 Gollwitzer H, Suren C, Strüwind C, et al. The natural alpha angle of the femoral head-neck junction: a cross-sectional CT study in 1312 femurs. Bone Joint J 2018;100-B(05):570-578

53 Mascarenhas VV, Rego P, Dantas P, et al. Can we discriminate symptomatic hip patients from asymptomatic volunteers based on anatomic predictors? A 3-dimensional magnetic resonance study on cam, pincer, and spinopelvic parameters. Am J Sports Med 2018;46(13):3097-3110

$54 \mathrm{Ng}$ KC, Mantovani G, Lamontagne M, Labrosse MR, Beaulé PE. Increased hip stresses resulting from a cam deformity and decreased femoral neck-shaft angle during level walking. Clin Orthop Relat Res 2017;475(04):998-1008

55 Sutter R, Dietrich TJ, Zingg PO, Pfirrmann CWA. How useful is the alpha angle for discriminating between symptomatic patients with cam-type femoroacetabular impingement and asymptomatic volunteers? Radiology 2012;264(02):514-521 
56 Wiberg G. Studies on dysplastic acetabula and congenital subluxation of the hip joint. With special reference to the complication of osteoarthritis. Acta Chir Scand 1939;83(Suppl 58):28-38

57 Werner CML, Ramseier LE, Ruckstuhl T, et al. Normal values of Wiberg's lateral center-edge angle and Lequesne's acetabular index-a coxometric update. Skeletal Radiol 2012;41(10): $1273-1278$

58 Fischer CS, Kühn J-P, Ittermann T, et al. What are the reference values and associated factors for center-edge angle and alpha angle? A population-based study. Clin Orthop Relat Res 2018; 476(11):2249-2259

59 Ogata S, Moriya H, Tsuchiya K, Akita T, Kamegaya M, Someya M. Acetabular cover in congenital dislocation of the hip. J Bone Joint Surg Br 1990;72(02):190-196

60 Egund N. Comment on Mittal et al: Defining the lateral edge of the femoroacetabular articulation: correlation analysis between radiographs and computed tomography. J Child Orthop 2017;11 (03):240-241

61 Wylie JD, Kapron AL, Peters CL, Aoki SK, Maak TG. Relationship between the lateral center-edge angle and 3-dimensional acetabular coverage. Orthop J Sports Med 2017;5(04): 2325967117700589

62 Mittal A, Bomar JD, Jeffords ME, Huang M-T, Wenger DR, Upasani $\mathrm{VV}$. Defining the lateral edge of the femoroacetabular articulation: correlation analysis between radiographs and computed tomography. J Child Orthop 2016;10(05):365-370

63 Tönnis D, Heinecke A. Acetabular and femoral anteversion: relationship with osteoarthritis of the hip. J Bone Joint Surg Am 1999;81(12):1747-1770

64 Zingg PO, Werner CML, Sukthankar A, Zanetti M, Seifert B, Dora $C$. The anterior center edge angle in Lequesne's false profile view: interrater correlation, dependence on pelvic tilt and correlation to anterior acetabular coverage in the sagittal plane. A cadaver study. Arch Orthop Trauma Surg 2009;129(06):787-791

65 Kalberer F, Sierra RJ, Madan SS, Ganz R, Leunig M. Ischial spine projection into the pelvis : a new sign for acetabular retroversion. Clin Orthop Relat Res 2008;466(03):677-683

66 Siebenrock KA, Kistler L, Schwab JM, Büchler L, Tannast M. The acetabular wall index for assessing anteroposterior femoral head coverage in symptomatic patients. Clin Orthop Relat Res 2012; 470(12):3355-3360

67 Laborie LB, Lehmann TG, Engesæter IO, Eastwood DM, Engesæter LB, Rosendahl K. Prevalence of radiographic findings thought to be associated with femoroacetabular impingement in a population-based cohort of 2081 healthy young adults. Radiology 2011; 260(02):494-502

68 Werner CM, Copeland CE, Stromberg J, Ruckstuhl T. Correlation of the cross-over ratio of the cross-over sign on conventional pelvic radiographs with computed tomography retroversion measurements. Skeletal Radiol 2010;39(07):655-660

69 Kappe T, Kocak T, Neuerburg C, Lippacher S, Bieger R, Reichel H. Reliability of radiographic signs for acetabular retroversion. Int Orthop 2011;35(06):817-821

70 Ross JR, Tannenbaum EP, Nepple JJ, Kelly BT, Larson CM, Bedi A. Functional acetabular orientation varies between supine and standing radiographs: implications for treatment of femoroacetabular impingement. Clin Orthop Relat Res 2015;473(04): 1267-1273

71 Anda S, Terjesen T, Kvistad KA, Svenningsen S. Acetabular angles and femoral anteversion in dysplastic hips in adults: CT investigation. J Comput Assist Tomogr 1991;15(01):115-120

72 Chadayammuri V, Garabekyan T, Jesse M-K, et al. Measurement of lateral acetabular coverage: a comparison between CT and plain radiography. J Hip Preserv Surg 2015;2(04):392-400

73 Murphy SB, Kijewski PK, Millis MB, Harless A. Acetabular dysplasia in the adolescent and young adult. Clin Orthop Relat Res 1990;(261):214-223
74 Grammatopoulos G, Speirs AD, Ng KCG, et al. Acetabular and spino-pelvic morphologies are different in subjects with symptomatic cam femoro-acetabular impingement. J Orthop Res 2018;36(07):1840-1848

75 Anda S, Svenningsen S, Dale LG, Benum P. The acetabular sector angle of the adult hip determined by computed tomography. Acta Radiol Diagn (Stockh) 1986;27(04):443-447

76 Visser JD, Jonkers A, Hillen B. Hip joint measurements with computerized tomography. J Pediatr Orthop 1982;2(02): 143-146

77 Reikerås O, Bjerkreim I, Kolbenstvedt A. Anteversion of the acetabulum and femoral neck in normals and in patients with osteoarthritis of the hip. Acta Orthop Scand 1983;54(01):18-23

78 Jamali AA, Mladenov K, Meyer DC, et al. Anteroposterior pelvic radiographs to assess acetabular retroversion: high validity of the “cross-over-sign.". J Orthop Res 2007;25(06):758-765

79 Laborie LB, Engesæter IØ, Lehmann TG, et al. Radiographic measurements of hip dysplasia at skeletal maturity-new reference intervals based on 2,038 19-year-old Norwegians. Skeletal Radiol 2013;42(07):925-935

80 Engesæter IO, Laborie LB, Lehmann TG, et al. Prevalence of radiographic findings associated with hip dysplasia in a population-based cohort of 2081 19-year-old Norwegians. Bone Joint J 2013;95-B(02):279-285

81 Wells J, Nepple JJ, Crook K, et al. Femoral morphology in the dysplastic hip: three-dimensional characterizations with $\mathrm{CT}$. Clin Orthop Relat Res 2017;475(04):1045-1054

82 Dandachli W, Ul Islam S, Tippett R, Hall-Craggs MA, Witt JD. Analysis of acetabular version in the native hip: comparison between 2D axial CT and 3D CT measurements. Skeletal Radiol 2011;40(07):877-883

83 Stem ES, O'Connor MI, Kransdorf MJ, Crook J. Computed tomography analysis of acetabular anteversion and abduction. Skeletal Radiol 2006;35(06):385-389

84 Kang ACL, Gooding AJ, Coates MH, Goh TD, Armour P, Rietveld J. Computed tomography assessment of hip joints in asymptomatic individuals in relation to femoroacetabular impingement. Am J Sports Med 2010;38(06):1160-1165

85 Larson CM, Moreau-Gaudry A, Kelly BT, et al. Are normal hips being labeled as pathologic? A CT-based method for defining normal acetabular coverage. Clin Orthop Relat Res 2015;473 (04):1247-1254

86 Nötzli HP, Wyss TF, Stoecklin CH, Schmid MR, Treiber K, Hodler J. The contour of the femoral head-neck junction as a predictor for the risk of anterior impingement. J Bone Joint Surg Br 2002;84 (04):556-560

87 Bouma H, Slot N-J, Toogood P, Pollard T, van Kampen P, Hogervorst T. Where is the neck? Alpha angle measurement revisited. Acta Orthop 2014;85(02):147-151

88 Lohan DG, Seeger LL, Motamedi K, Hame S, Sayre J. Cam-type femoral-acetabular impingement: is the alpha angle the best MR arthrography has to offer? Skeletal Radiol 2009;38(09): 855-862

89 Barton C, Salineros MJ, Rakhra KS, Beaulé PE. Validity of the alpha angle measurement on plain radiographs in the evaluation of cam-type femoroacetabular impingement. Clin Orthop Relat Res 2011;469(02):464-469

90 Yanke AB, Khair MM, Stanley R, et al. Sex differences in patients with CAM deformities with femoroacetabular impingement: 3 dimensional computed tomographic quantification. Arthroscopy 2015;31(12):2301-2306

91 Frank JM, Harris JD, Erickson BJ, et al. Prevalence of femoroacetabular impingement imaging findings in asymptomatic volunteers: a systematic review. Arthroscopy 2015;31(06): 1199-1204

92 Hack K, Di Primio G, Rakhra K, Beaulé PE. Prevalence of cam-type femoroacetabular impingement morphology in asymptomatic volunteers. J Bone Joint Surg Am 2010;92(14):2436-2444 
93 Golfam M, Di Primio LA, Beaulé PE, Hack K, Schweitzer ME. Alpha angle measurements in healthy adult volunteers vary depending on the MRI plane acquisition used. Am J Sports Med 2017;45 (03):620-626

94 Reichenbach S, Jüni P, Werlen S, et al. Prevalence of cam-type deformity on hip magnetic resonance imaging in young males: a cross-sectional study. Arthritis Care Res (Hoboken) 2010;62(09): 1319-1327

95 Ganz R, Parvizi J, Beck M, Leunig M, Nötzli H, Siebenrock KA. Femoroacetabular impingement: a cause for osteoarthritis of the hip. Clin Orthop Relat Res 2003;(417):112-120

96 Ganz R, Gill TJ, Gautier E, Ganz K, Krügel N, Berlemann U. Surgical dislocation of the adult hip a technique with full access to the femoral head and acetabulum without the risk of avascular necrosis. J Bone Joint Surg Br 2001;83(08):1119-1124

97 Agricola R, Waarsing JH, Thomas GE, et al. Cam impingement: defining the presence of a cam deformity by the alpha angle: data from the CHECK cohort and Chingford cohort. Osteoarthritis Cartilage 2014;22(02):218-225

98 Fraitzl CR, Kappe T, Pennekamp F, Reichel H, Billich C. Femoral head-neck offset measurements in 339 subjects: distribution and implications for femoroacetabular impingement. Knee Surg Sports Traumatol Arthrosc 2013;21(05):1212-1217

99 Ito K, Minka MA II, Leunig M, Werlen S, Ganz R. Femoroacetabular impingement and the cam-effect. An MRI-based quantitative anatomical study of the femoral head-neck offset. J Bone Joint Surg Br 2001;83(02):171-176

100 Eijer H, Leunig M, Mahomed MN, Ganz R. Cross-table lateral radiographs for screening of anterior femoral head-neck offset in patients with femoro-acetabular impingement. Hip 2001;11 (01):37-41

101 Beaulé PE, Harvey N, Zaragoza E, Le Duff MJ, Dorey FJ. The femoral head/neck offset and hip resurfacing. J Bone Joint Surg Br 2007; 89(01):9-15

102 Pollard TCB, Villar RN, Norton MR, et al. Femoroacetabular impingement and classification of the cam deformity: the reference interval in normal hips. Acta Orthop 2010;81(01):134-141

103 Ehrmann C, Rosskopf AB, Pfirrmann CWA, Sutter R. Beyond the alpha angle: Alternative measurements for quantifying camtype deformities in femoroacetabular impingement. J Magn Reson Imaging 2015;42(04):1024-1031

104 Bobroff ED, Chambers HG, Sartoris DJ, Wyatt MP, Sutherland DH. Femoral anteversion and neck-shaft angle in children with cerebral palsy. Clin Orthop Relat Res 1999;(364):194-204

105 Ng KCG, Lamontagne M, Labrosse MR, Beaulé PE. Hip joint stresses due to cam-type femoroacetabular impingement: a systematic review of finite element simulations. PLoS ONE 2016;11(01):e0147813

106 Guevara CJ, Pietrobon R, Carothers JT, Olson SA, Vail TP. Comprehensive morphologic evaluation of the hip in patients with symptomatic labral tear. Clin Orthop Relat Res 2006;453(453): 277-285

107 Boese CK, Dargel J, Oppermann J, et al. The femoral neck-shaft angle on plain radiographs: a systematic review. Skeletal Radiol 2016;45(01):19-28

108 Boese CK, Jostmeier J, Oppermann J, et al. The neck shaft angle: CT reference values of 800 adult hips. Skeletal Radiol 2016;45 (04):455-463. Doi: 10.1007/s00256-015-2314-2

109 Gosvig KK, Jacobsen S, Palm H, Sonne-Holm S, Magnusson E. A new radiological index for assessing asphericity of the femoral head in cam impingement. J Bone Joint Surg Br 2007;89(10): 1309-1316

110 Rego PRA, Mascarenhas V, Oliveira FS, et al. Morphologic and angular planning for cam resection in femoro-acetabular impingement: value of the omega angle. Int Orthop 2016;40(10): 2011-2017

111 Rego P, Mascarenhas V, Collado D, Coelho A, Barbosa L, Ganz R. Arterial topographic anatomy near the femoral head-neck per- foration with surgical relevance. J Bone Joint Surg Am 2017;99 (14):1213-1221

112 Murphy SB, Simon SR, Kijewski PK, Wilkinson RH, Griscom NT. Femoral anteversion. J Bone Joint Surg Am 1987;69(08): 1169-1176

113 Gelberman RH, Cohen MS, Desai SS, Griffin PP, Salamon PB, O'Brien TM. Femoral anteversion. A clinical assessment of idiopathic intoeing gait in children.J Bone Joint Surg Br 1987;69(01): 75-79

114 Tönnis D, Heinecke A. Diminished femoral antetorsion syndrome: a cause of pain and osteoarthritis. J Pediatr Orthop 1991;11(04):419-431

115 Sutter R, Dietrich TJ, Zingg PO, Pfirrmann CWA. Femoral antetorsion: comparing asymptomatic volunteers and patients with femoroacetabular impingement. Radiology 2012;263(02): 475-483

116 Gómez-Hoyos J, Schröder R, Reddy M, Palmer IJ, Martin HD. Femoral neck anteversion and lesser trochanteric retroversion in patients with ischiofemoral impingement: a case-control magnetic resonance imaging study. Arthroscopy 2016;32(01):13-18

117 Botser IB, Ozoude GC, Martin DE, Siddiqi AJ, Kuppuswami S, Domb BG. Femoral anteversion in the hip: comparison of measurement by computed tomography, magnetic resonance imaging, and physical examination. Arthroscopy 2012;28(05): 619-627

118 Kelly BT, Bedi A, Robertson CM, Dela Torre K, Giveans MR, Larson $\mathrm{CM}$. Alterations in internal rotation and alpha angles are associated with arthroscopic cam decompression in the hip. Am J Sports Med 2012;40(05):1107-1112

119 Kraeutler MJ, Chadayammuri V, Garabekyan T, Mei-Dan O. Femoral version abnormalities significantly outweigh effect of cam impingement on hip internal rotation. J Bone Joint Surg Am 2018;100(03):205-210

120 Lerch TD, Todorski IAS, Steppacher SD, et al. Prevalence of femoral and acetabular version abnormalities in patients with symptomatic hip disease: a controlled study of 538 hips. Am J Sports Med 2018;46(01):122-134

121 Tibor LM, Liebert G, Sutter R, Impellizzeri FM, Leunig M. Two or more impingement and/or instability deformities are often present in patients with hip pain. Clin Orthop Relat Res 2013; 471(12):3762-3773

122 Fritz B, Bensler S, Leunig M, Zingg PO, Pfirrmann CWA, Sutter R. MRI Assessment of supra- and infratrochanteric femoral torsion: association with femoroacetabular impingement and hip dysplasia. AJR Am J Roentgenol 2018;211(01):155-161

123 McCarthy JC, Noble PC, Villar RN. Hip Joint Restoration. New York, NY: Springer; 2016

124 Fuller CB, Farnsworth CL, Bomar JD, et al. Femoral version: comparison among advanced imaging methods. J Orthop Res 2018;36(05):1536-1542

125 Sutter R, Dietrich TJ, Zingg PO, Pfirrmann CWA. Assessment of femoral antetorsion with MRI: comparison of oblique measurements to standard transverse measurements. AJR Am J Roentgenol 2015;205(01):130-135

126 Hartel MJ, Petersik A, Schmidt A, et al. Determination of femoral neck angle and torsion angle utilizing a novel three-dimensional modeling and analytical technology based on CT datasets. PLoS ONE 2016;11(03):e0149480

127 Kaiser P, Attal R, Kammerer M, et al. Significant differences in femoral torsion values depending on the CT measurement technique. Arch Orthop Trauma Surg 2016;136(09):1259-1264

128 Schneider B, Laubenberger J, Jemlich S, Groene K, Weber HM, Langer $\mathrm{M}$. Measurement of femoral antetorsion and tibial torsion by magnetic resonance imaging. Br J Radiol 1997;70(834):575-579

129 Tomczak RJ, Guenther KP, Rieber A, Mergo P, Ros PR, Brambs HJ. MR imaging measurement of the femoral antetorsional angle as a new technique: comparison with CT in children and adults. AJR Am J Roentgenol 1997;168(03):791-794 
130 Berryman F, Pynsent P, McBryde C. A semi-automated method for measuring femoral shape to derive version and its comparison with existing methods. Int J Numer Methods Biomed Eng 2014;30(11):1314-1325

131 Tardieu C, Hasegawa K, Haeusler M. How did the pelvis and vertebral column become a functional unit during the transition from occasional to permanent bipedalism? Anat Rec (Hoboken) 2017;300(05):912-931

132 Duval-Beaupère G, Schmidt C, Cosson P. A Barycentremetric study of the sagittal shape of spine and pelvis: the conditions required for an economic standing position. Ann Biomed Eng 1992;20(04):451-462

133 Legaye J, Duval-Beaupère G, Hecquet J, Marty C. Pelvic incidence: a fundamental pelvic parameter for three-dimensional regulation of spinal sagittal curves. Eur Spine J 1998;7(02):99-103

$134 \mathrm{Zhu}$ Z, Xu L, Zhu F, et al. Sagittal alignment of spine and pelvis in asymptomatic adults: norms in Chinese populations. Spine 2014;39(01):E1-E6

135 Weinberg DS, Liu RW, Xie KK, Morris WZ, Gebhart JJ, Gordon ZL. Increased and decreased pelvic incidence, sagittal facet joint orientations are associated with lumbar spine osteoarthritis in a large cadaveric collection. International Orthopaedics 2017;41 (08):1593-1600

136 Gebhart JJ, Weinberg DS, Bohl MS, Liu RW. Relationship between pelvic incidence and osteoarthritis of the hip. Bone Joint Res 2016;5(02):66-72

137 Ng KCG, Lamontagne M, Jeffers JRT, Grammatopoulos G, Beaulé $\mathrm{PE}$. Anatomic predictors of sagittal hip and pelvic motions in patients with a cam deformity. Am J Sports Med 2018;46(06): 1331-1342

138 Chen H-F, Zhao C-Q. Pelvic incidence variation among individuals: functional influence versus genetic determinism. J Orthop Surg Res 2018;13(01):59

139 Moon JW, Shinn JK, Ryu D, Oh S-Y, Shim YS, Yoon SH. Pelvic incidence can be changed not only by age and sex, but also by posture used during imaging. Korean J Spine 2017;14(03):77-83

140 Endo K, Suzuki H, Nishimura H, Tanaka H, Shishido T, Yamamoto K. Sagittal lumbar and pelvic alignment in the standing and sitting positions. J Orthop Sci 2012;17(06):682-686

141 Ozkunt O, Sariyilmaz K, Gemalmaz HC, Kaya O, Dikici F. Comparison of spinal sagittal parameters by time of day in a healthy working population: Do we bend during the day? J Back Musculoskeletal Rehabil 2018;31(02):381-388

142 Park S-A, Kwak D-S, Cho H-J, Min D-U. Changes of spinopelvic parameters in different positions. Arch Orthop Trauma Surg 2017;137(09):1223-1232
143 Lee CS, Chung SS, Kang KC, Park SJ, Shin SK. Normal patterns of sagittal alignment of the spine in young adults radiological analysis in a Korean population. Spine 2011;36(25): E1648-E1654

144 Mac-Thiong J-M, Roussouly P, Berthonnaud E, Guigui P. Age- and sex-related variations in sagittal sacropelvic morphology and balance in asymptomatic adults. Eur Spine J 2011;20 (Suppl 5):572-577

145 Sudhir G, Acharya SK L K, Chahal R. Radiographic analysis of the sacropelvic parameters of the spine and their correlation in normal asymptomatic subjects. Global Spine J 2016;6(02): 169-175

146 Asai Y, Tsutsui S, Oka H, et al. Sagittal spino-pelvic alignment in adults: the Wakayama spine study. PLoS ONE 2017;12(06): e0178697

147 Sohn S, Chung CK, Kim YJ, et al. Sagittal spinal alignment in asymptomatic patients over 30 years old in the Korean population. Acta Neurochir (Wien) 2017;159(06):1119-1128

148 Le Huec JC, Hasegawa K. Normative values for the spine shape parameters using 3D standing analysis from a database of 268 asymptomatic Caucasian and Japanese subjects. Eur Spine J 2016;25(11):3630-3637

149 Romero-Vargas S, Zárate-Kalfópulos B, Otero-Cámara E, et al. The impact of body mass index and central obesity on the spinopelvic parameters: a correlation study. Eur Spine J 2013;22(04): 878-882

150 Roussouly P, Pinheiro-Franco JL. Biomechanical analysis of the spino-pelvic organization and adaptation in pathology. Eur Spine J 2011;20(Suppl 5):609-618

151 Saltychev M, Pernaa K, Seppänen M, Mäkelä K, Laimi K. Pelvic incidence and hip disorders. Acta Orthop 2018;89(01):66-70

152 Tiziani S, Gautier L, Farei-Campagna J, et al. Correlation of pelvic incidence with radiographical parameters for acetabular retroversion: a retrospective radiological study. BMC Med Imaging 2015;15(September):39

153 Pierannunzii L. Pelvic posture and kinematics in femoroacetabular impingement: a systematic review. J Orthop Traumatol 2017;18(03):187-196

154 Palmer A, Fernquest S, Rombach I, et al. Diagnostic and prognostic value of delayed Gadolinium Enhanced Magnetic Resonance Imaging of Cartilage (dGEMRIC) in early osteoarthritis of the hip. Osteoarthritis Cartilage 2017;25(09):1468-1477

155 Bittersohl B, Hosalkar HS, Apprich S, Werlen SA, Siebenrock KA, Mamisch TC. Comparison of pre-operative dGEMRIC imaging with intra-operative findings in femoroacetabular impingement: preliminary findings. Skeletal Radiol 2011;40(05):553-561 